Pacific Northwest

National Laboratory

Operated by Battelle for the

U.S. Department of Energy

\section{Influence of Clastic Dikes on Vertical Migration of Contaminants in the Vadose Zone at Hanford}

\author{
C. Murray \\ A. Ward \\ J. Wilson
}

March 2003 


\title{
DISCLAIMER
}

This report was prepared as an account of work sponsored by an agency of the United States Government. Neither the United States Government nor any agency thereof, nor Battelle Memorial Institute, nor any of their employees, makes any warranty, express or implied, or assumes any legal liability or responsibility for the accuracy, completeness, or usefulness of any information, apparatus, product, or process disclosed, or represents that its use would not infringe privately owned rights. Reference herein to any specific commercial product, process, or service by trade name, trademark, manufacturer, or otherwise does not necessarily constitute or imply its endorsement, recommendation, or favoring by the United States Government or any agency thereof, or Battelle Memorial Institute. The views and opinions of authors expressed herein do not necessarily state or reflect those of the United States Government or any agency thereof.

\author{
PACIFIC NORTHWEST NATIONAL LABORATORY \\ operated by \\ BATTELLE \\ for the \\ UNITED STATES DEPARTMENT OF ENERGY \\ under Contract DE-AC06-76RL01830
}

Ty 


\title{
FINAL REPORT
}

\section{U.S. Department of Energy}

\section{Influence of Clastic Dikes on Vertical Migration of Contaminants in the Vadose Zone at Hanford}

\author{
Principal Investigator: Christopher J. Murray \\ Institution: Pacific Northwest National Laboratory \\ P.O. Box 999, MSIN K6-81 \\ Richland, WA 99352 \\ 509-376-5848 (phone) \\ Chris.Murray@pnl.gov \\ Co-Investigator: Anderson L. Ward \\ Institution: Pacific Northwest National Laboratory \\ P.O. Box 999, MSIN K9-33 \\ Richland, WA 99352 \\ 509-372-6114 (phone) \\ Andy.Ward@pnl.gov \\ Co-Principal Investigator: John L. Wilson \\ Institution: Department of Earth and Environmental Science \\ New Mexico Institute of Mining and Technology \\ Socorro, NM 87801 \\ 505-835-5308 (phone) \\ jwilson@nmt.edu \\ Project Number: 70193 \\ Project Duration: October 1, 1999, to March 14, 2003
}




\section{Table of Contents}

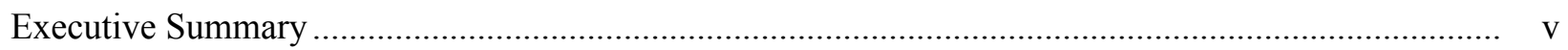

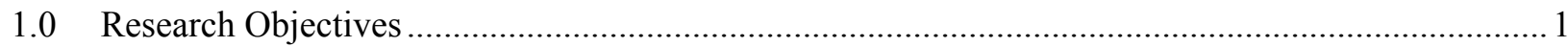

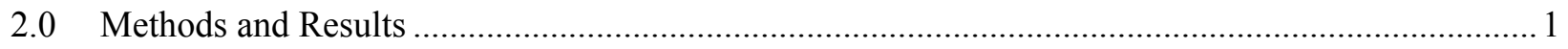

2.1 Statistical Analysis of Large-Scale Structure of Clastic Dikes ............................................ 1

2.2 Simulation of Large-Scale Structure of Clastic Dikes........................................................ 5

2.2.1 Post-Processing of the Simulated Polygon Networks ............................................... 7

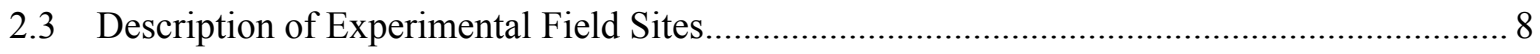

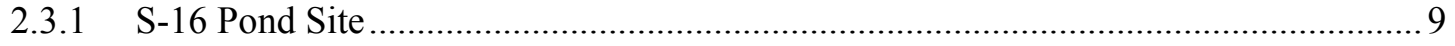

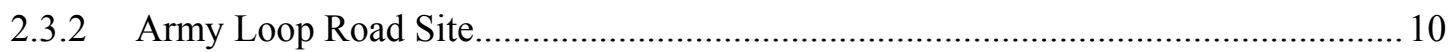

2.4 Measurement of Geological and Hydrogeological Properties................................................ 10

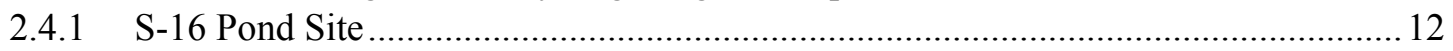

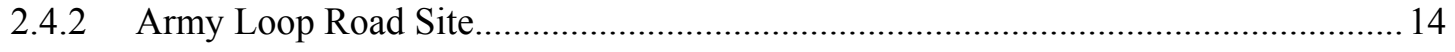

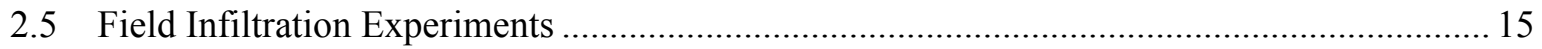

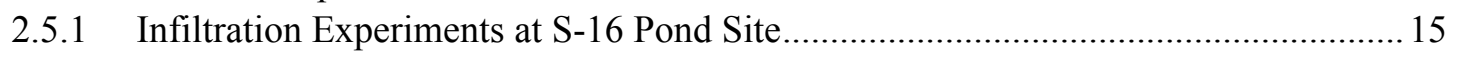

2.5.2 Infiltration Experiments at Army Loop Road Site ................................................. 16

2.6 Modeling of Field Infiltration Experiments at the Army Loop Road Site ............................ 17

2.6.1 Geologic Interpretation for Model Development ..................................................... 17

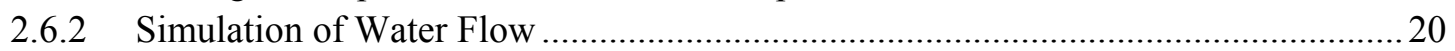

2.6.3 Model Parameters..................................................................................................... 21

2.6.4 Subsurface Moisture Patterns and their Relation to Surface Flux .............................. 23

2.6.5 Subsurface Flow Networks and their Relation to Surface Flux ................................25

3.0 Relevance, Impact, and Technology Transfer..........................................................................2 27

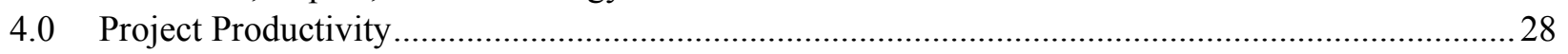

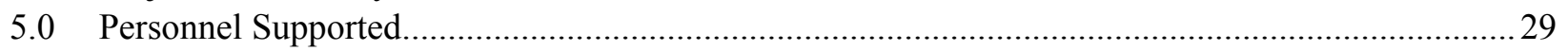

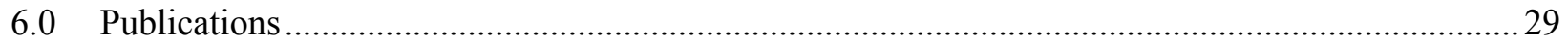

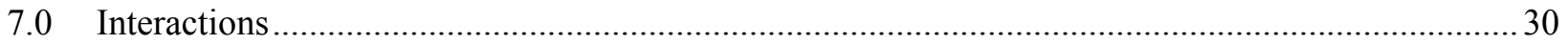

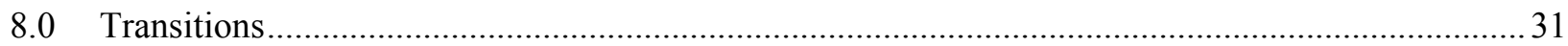

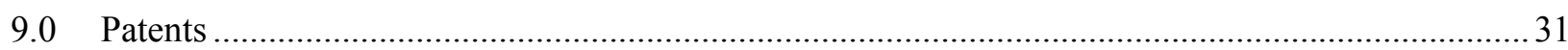

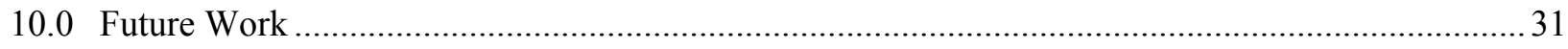

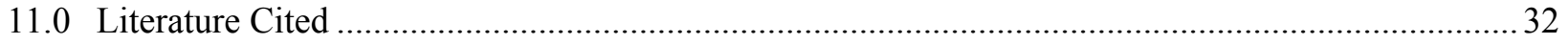




\section{Executive Summary}

The purpose of this study was to examine the hypothesis that clastic dikes could form a preferential flow path through the vadose zone to the water table at the Hanford Site. Clastic dikes are subvertical structures that form within sedimentary sequences after deposition and cut across the original sedimentary layers. They are common throughout the Hanford Site, often occurring in organized polygonal networks.

In the initial phase of the project, we analyzed the large-scale geometry of the clastic dikes and developed an algorithm for simulating their spatial distribution. This result will be useful in providing maps of the potential distribution of clastic dikes in areas where they are not exposed at the surface (e.g., where covered by windblown sand or construction of facilities like tank farms at the surface). In addition to the study of the large-scale distribution of the dikes, a major focus of the project was on field, laboratory, and modeling studies of the hydrogeological properties of the clastic dikes and the effect that they have on transport of water through the vadose zone. These studies were performed at two field locations at the Hanford Site. We performed an extensive series of field and laboratory measurements of a large number of samples from the clastic dikes, linked with infrared (IR) and visual imagery of the clastic dikes and surrounding matrix. We developed a series of correlations from the sample data that allowed us to estimate the unsaturated hydraulic conductivity of the dike and matrix at an extremely high resolution (approximately $1 \mathrm{~mm}$ ). The resulting grids, each of which measured several meters on a side and included nearly four million grid nodes, were used to study the distribution of moisture between the clastic dike and surrounding matrix, as well as the relative velocities that moisture would have through the clastic dike and matrix for a number of different recharge scenarios.

Results show the development of complex flow networks that depend on input flux rates and boundary type and that may sometimes mask the underlying heterogeneity. The networks occupy two complementary states: a high-permeability region in the fine-textured media at low fluxes and a high- 
permeability region in the coarse-textured media at high fluxes. Transition between the two states occurred at an input flux of about $100 \mathrm{~mm} \mathrm{yr}^{-1}$. At this input flux, preferential channels essentially disappear with the dike and host matrix conducting at similar rates. This suggests that clastic dikes might serve as a conduit for more rapid movement of moisture and mobile contaminants to the water table, but only under a restricted set of recharge (or leak) conditions. However, owing to the relatively high content of reactive minerals, especially clay, that is found in the clastic dikes, the movement of reactive contaminants like heavy metals and radionuclides may be restricted.

The field site developed for this project, as well as the data and numerical models, are now the focus of several ongoing studies funded by the Hanford Groundwater Protection Program's Science and Technology (S\&T) Project. These studies focus on collecting datasets to support conceptual model development and model calibration, the development and use of advanced scaling methods to facilitate inverse modeling of heterogeneous systems, and the identification of appropriate parameters for predictive modeling of field-scale reactive transport. 


\subsection{Research Objectives}

This research project addressed the effect of clastic dikes on contaminant transport in the vadose zone. Clastic dikes are vertically oriented subsurface heterogeneities that are common at the Hanford Site, including in the subsurface sediments below the tank farms in the 200 West Area. Previous studies have suggested that clastic dikes may provide a fast path for transport of leaking fluid from the tanks through the vadose zone because they cut through the horizontally layered sediments at the site.

The research tested the hypothesis that clastic dikes at the Hanford Site provide preferential pathways that enhance the vertical movement of moisture and contaminants through the vadose zone. Current flow and transport models of the vadose zone at the 200 Areas are based on relatively simple hydrogeologic models that assume horizontally layered sediments with no preferential vertical flow paths. To address those scientific needs, our research included field and modeling studies of the large-scale spatial distribution of clastic dikes, the hydrologic properties within dikes, and the potential effect of clastic dikes on fluid flow through the vadose zone. The data and models of the clastic dike networks produced for this project should be directly applicable to fate and transport studies conducted at the Hanford tank farms.

\subsection{Methods and Results}

\subsection{Statistical Analysis of Large-Scale Structure of Clastic Dikes}

Figure 1 shows the dikes over the western portion of the Hanford Site as mapped into a Geographic Information System (GIS) from aerial photographs. Dikes commonly have greater moisture-holding capacity than host sediments because they are finer-grained, and the dikes can thus be revealed through the surface vegetation patterns, even where the dikes are not directly exposed at the surface. Note that the map does not show the full spatial extent of the clastic dike network. Even in areas where the dike network is not mapped in Figure 1, the dike network appears to be present, but is covered by surficial sediment or man-made structures. Throughout the study area the dikes tend to occur in a regular polygonal network (Figure 1). The GIS was also used to retrieve information about the polygons formed by the dikes including their area and the number of sides present in the polygons. In addition, four field traverses were made across the dike swarm (Figure 1), and the spacing and widths of dikes crossed during the traverses were measured. The edges of the dikes were interpreted to be the boundaries where the density of vegetation changed.

We conducted statistical analyses of the data, including standard univariate analyses of the properties of the dikes and associated polygons. We used circular statistics (Davis 2002) to study the orientation of the clastic dikes. We also used the GIS to extract the centroids of the clastic dike polygons and analyze their spatial distribution using spatial statistics, including refined nearest neighbor analysis using software developed by Moeur (1993). 


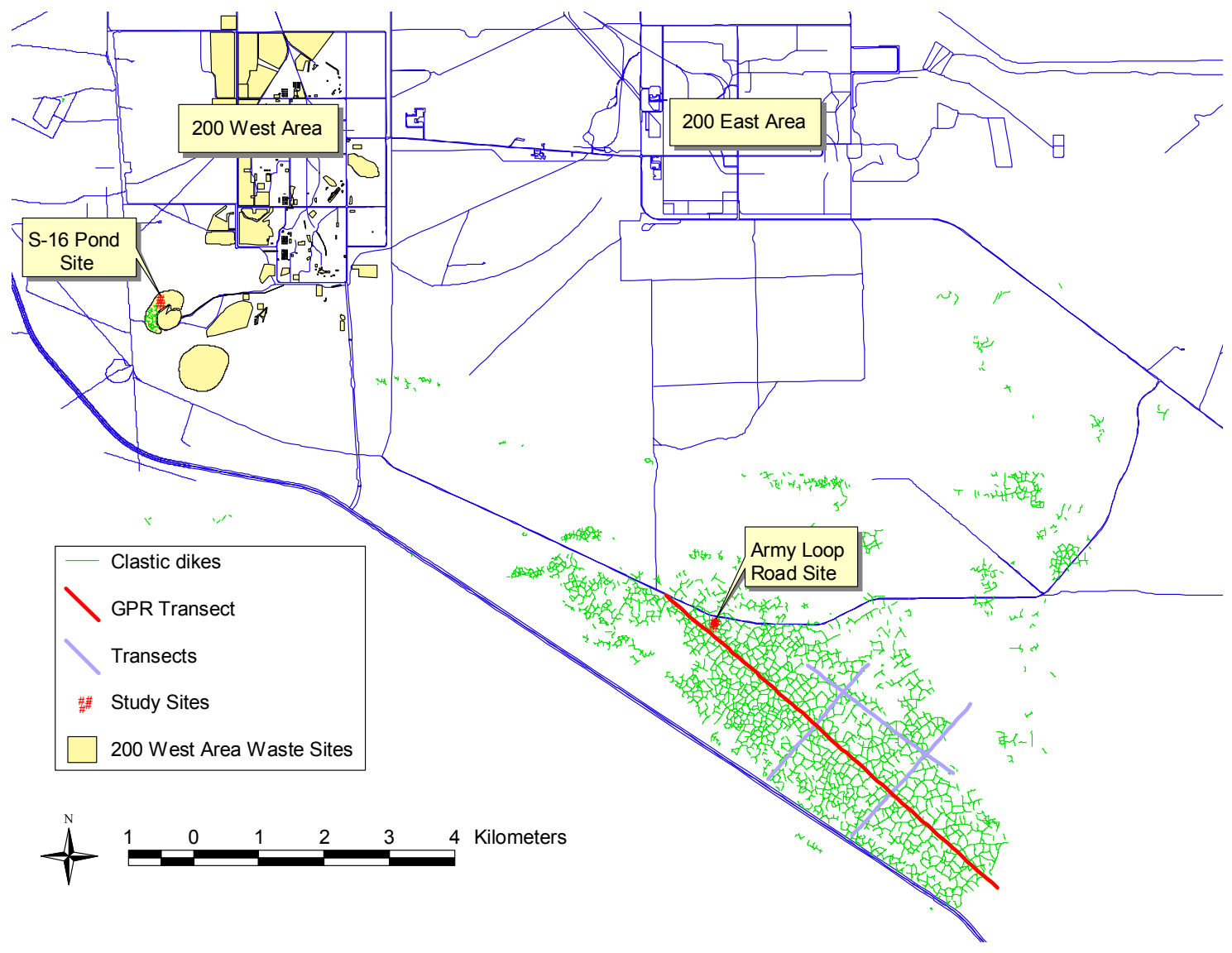

Figure 1. Map of Clastic Dike Networks Exposed at the Hanford Site. Clastic dikes appear to be common across the entire Hanford Site, but are usually covered by surface sediment deposits or cultural features.

In 2000, the project used remote sensing and ground-penetrating radar surveys to describe the large-scale distribution of the clastic dikes along Army Loop Road in the 600 Area and at the 216-S-16 pond. Figure 1 shows the dikes at the two sites as mapped into a GIS from air photographs. Over 3,800 dikes were digitized from the photographs and entered in the GIS. The GIS then was used to extract the lengths of the dikes (based on the distance between the digitized endpoints of each dike), area of the polygons (where each polygon is formed by a series of bounding clastic dikes), and the azimuth of the dikes. In addition, four field traverses were made across the dike swarm, and the widths of dikes crossed during the traverses were measured for 58 dikes within the network. The edges of the dikes were interpreted to be the boundaries where the density of vegetation changed (vegetation is thicker on the dikes than on the host soil because the dikes tend to hold more moisture). Excavation of a limited number of dikes suggested the vegetation change was a reliable method of estimating the width of the dikes.

The length distribution of the clastic dikes is positively skewed (Figure 2), with a mean length of about $60 \mathrm{~m}$, a median length of $55 \mathrm{~m}$, and with $90 \%$ of the dikes less than $115 \mathrm{~m}$ in length. The lengths of the longer dikes shown in Figure 2 may be artificial. Because the interpretations of the dikes from the aerial photo are based on the vegetation difference between the dikes and the adjacent matrix, incomplete 


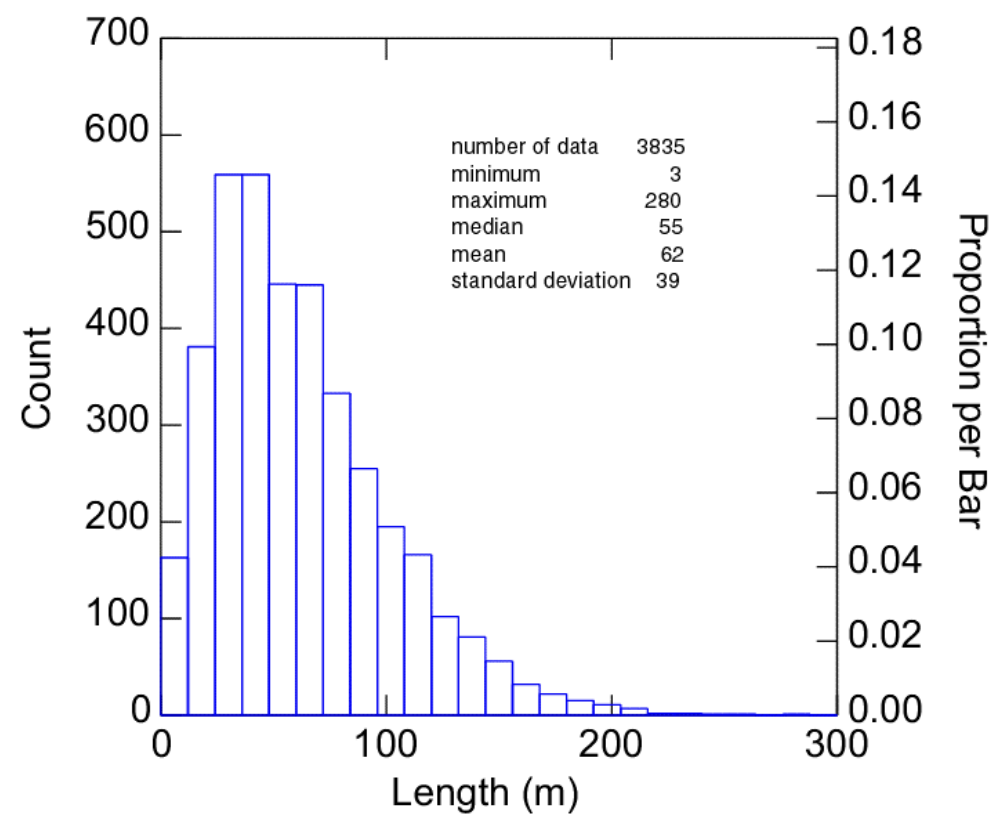

Figure 2. Histogram of Dike Lengths

exposure of the dikes, e.g., due to the presence of a cover of windblown sand, is inevitable. Therefore, some long dikes may consist of several segments because of cover obscuring the intersections along them. Figure 3 shows the width of 58 dikes based on the vegetation response. The mean width of the measured dikes is about $2 \mathrm{~m}$ and the distribution is symmetrical about the mean. The polygons within the dike network are predominantly four- or five-sided (Table 1), with three- and six-sided polygons less common.

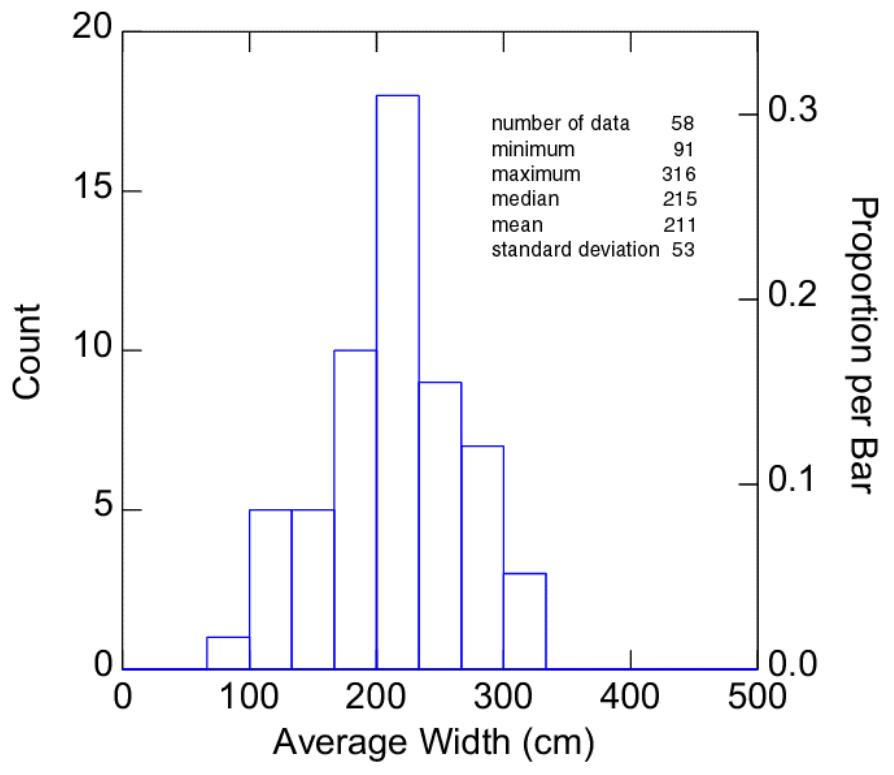

Figure 3. Histogram of Dike Widths 
Table 1. Number of Sides of Polygons in Army Loop Road Clastic Dike Network

\begin{tabular}{|l|l|l|l|l|l|l|l|l|l|l|l|l|l|}
\hline Number of sides & 3 & 4 & 5 & 6 & 7 & 8 & 9 & 10 & 11 & 13 & 15 & 19 & 22 \\
\hline Frequency & 39 & 263 & 195 & 51 & 13 & 7 & 2 & 2 & 3 & 1 & 1 & 1 & 1 \\
\hline
\end{tabular}

Figure 4 shows the rose diagram of the orientation angle of the 3835 dikes with a mean angle of $77.57^{\circ}$. The angle distribution was tested against the uniform distribution and there is no significant difference between the angle distributions observed in the clastic dikes and a uniform distribution (Figure 5).

Figure 6 shows a scatter plot of the polygon centroids of the 583 dike polygons for the network shown in Figure 1. The spatial pattern of the dike polygon centroids was investigated to determine if the polygon centroids are distributed randomly or follow some pattern. Modified Nearest Neighbor analysis (Moeur 1993) was conducted on the polygon centroid data set and the results indicated that the polygon centroids are not randomly distributed or clustered, but instead are distributed in a relatively uniform fashion in the study area with an average spacing between the centroids of about $60 \mathrm{~m}$.

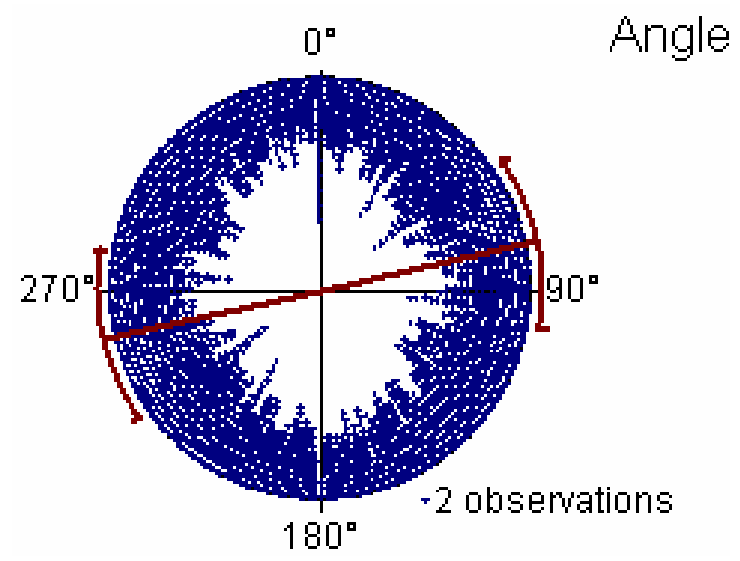

Figure 4. Rose Diagram of Clastic Dike Orientations

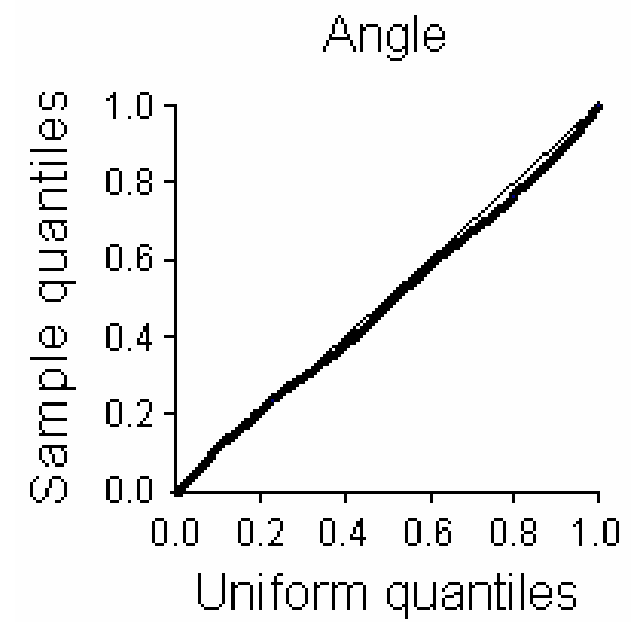

Figure 5. Results of Uniformity Test 


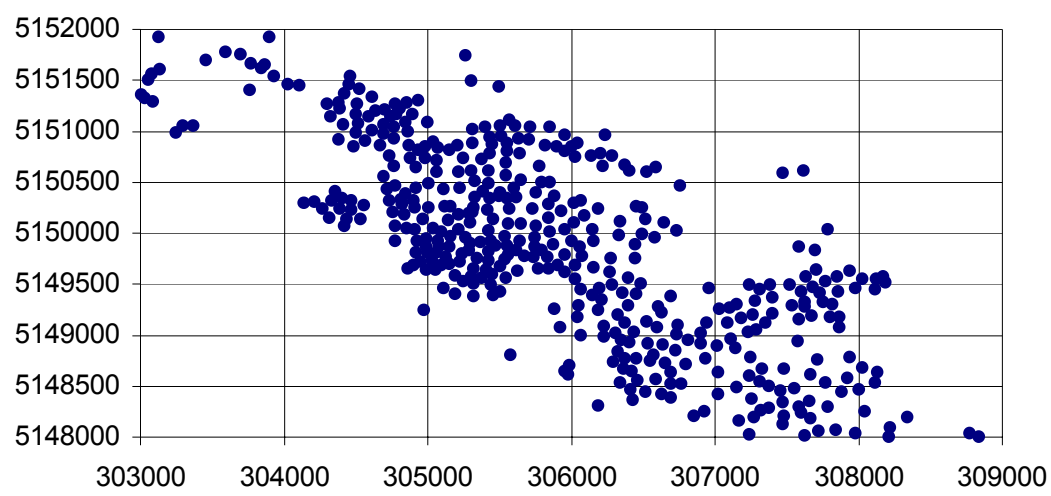

Figure 6. Scatter Plot of the 583 Polygon Centroids

From the above data analysis it can be seen that a dike system can be evaluated quantitatively by treating it as a polygonal network. The descriptive statistics and the histogram of the length and orientation angle distributions of the dike edges, the distribution of area, and perimeter of dike polygons, and the point patterns of dike polygon centroids are several measures that can be used to quantify the large-scale geometry of the clastic dikes.

\subsection{Simulation of Large-Scale Structure of Clastic Dikes}

In our proposal to the EMSP program, we originally suggested the use of fractal methods to generate fields with the large-scale geometry of the clastic dikes. Previous work has indicated that the spatial distribution of clastic dikes may possess a fractal distribution. Jolly et al. (1998) studied the distribution of clastic dikes in the Budden Canyon Formation of California and found they were highly ordered, with most dikes nearly perpendicular to the enclosing sediments and having a consistent strike direction. They found that the spacing between clastic dikes followed a power-law distribution that was invariant over 2.5 orders of magnitude. Their results indicated a strong tectonic control on the spatial distribution of the clastic dikes (Jolly et al. 1998). This conclusion is consistent with previous work on the spatial distribution of tectonically controlled fractures and faults, which has shown that faults and fractures often have a fractal distribution (e.g., Barton 1995; Barton and Zoback 1992; Cowie et al. 1996).

However, examination of the data on clastic dikes at Hanford indicated that the fractal methods used to generate spatial simulations of fractures would be inappropriate for the site. Although tectonically controlled clastic dikes do occur at the Hanford Site near Gable Mountain, they are not the dominant type of clastic dike at the Hanford Site (Fecht et al. 1998). The majority of the site, which is in the central portion of the Columbia Basin away from major tectonic features, is marked by regular polygon networks. The dikes in these networks commonly merge without truncation at simple or complex junctions (Fecht et al. 1998) and do not crosscut one another. The fractal methods discussed in the original proposal, e.g., the method of Acuna and Yortsos (1995), generate complex fracture patterns that are marked by cross-cutting intersections. Although those methods would be appropriate for generation of most tectonically controlled fracture networks, they would not be suitable for regular polygonal networks like those present over most of the Hanford Site, so an alternative simulation approach was developed. 
Visual inspection of the aerial photographs indicates that the regular networks formed by the clastic dikes are similar to mud cracks, basalt polygons, and other closed, space-filling geologic structures that form by cooling or drying. Davis (2002) indicates structures with that nature have been modeled using Voronoi polygons, so we developed a simulation approach using that structure to create synthetic models that mimic the large-scale geometry of clastic dikes. Because the dikes tend to be vertically oriented, only a $2 \mathrm{D}$ dike network is simulated. Subsequent elaboration of the method could be used to develop fully $3 \mathrm{D}$ models.

Using software developed by Moeur (1993), the proposed approach starts by simulating a set of polygonal centroids, which have the spatial pattern of the real dike system. In this way, the centroid spatial pattern of the simulated dike polygon preserves a major feature of the actual dike system by construction. A Voronoi polygon network is then constructed for each set of simulated polygon centroids. The Voronoi polygon network does not necessarily have the desired geometric and spatial features observed in the actual dike polygon system, but it provides a starting point. Simulated annealing is then applied to optimize the Voronoi polygon system by iteratively disturbing it to achieve the desired geometric and spatial characteristics observed in the polygonal dike networks. To achieve this goal, the angle and length distributions of the observed dike networks serve as the optimization targets. The polygon vertices in the Voronoi polygons are chosen stochastically in a sequential manner, and their coordinates are perturbed. To avoid geometric conflicts after perturbation such as cross over of the polygon edges, the perturbation is limited in the vicinity of the vertex to be perturbed. The vicinity is defined by the smallest separation of the vertex with the neighbor vertices. The length and orientation distributions are updated for each perturbation, and the objective function, which is the difference between the target and calculated dike length and orientation angles, is evaluated after each perturbation. Perturbations that lead to a lower objective function are accepted unconditionally. Detrimental perturbations that lead to a higher value of the objective function can also be accepted based on a probability defined by an analogous Boltzmann distribution (Deutsch and Cockerham 1994). Simulated annealing was suitable for this task because of its global optimization characteristics and its flexibility in the adoption of various objective function components.

The geometric properties of the 3,835 dikes and associated polygonal network discussed in the previous section were used as target properties for modeling the large-scale geometry of the dikes. Figure 7 shows a regularly distributed point pattern generated using software developed by Moeur (1993). That point distribution has the same average spacing as that found in the study area. The Voronoi polygon network generated from the point distribution, which served as the basis for simulation of a clastic dike network, is also shown in Figure 7. The comparison of the length and angle $c d f$ of the simulated polygon systems
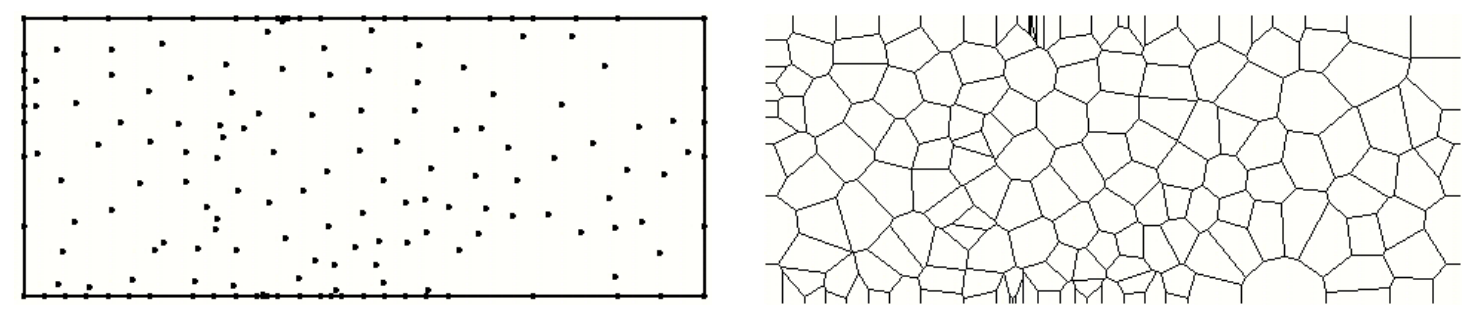

Figure 7. A Regularly Distributed Point Pattern (left) and the Corresponding Voronoi Polygon Network 
with their target $c d f s$ is shown in Figure 8 . Figure 8 shows that the angle distribution reproduction is better than the length distribution reproduction. There is a fair deviation in the upper portion of the length distributions. We mentioned previously that there may be artifacts in the longer length due to the incomplete exposure of the dikes in the network, which may be responsible for that deviation.

Figure 8 shows probability plots of the length and angle distribution of the reference dike system plotted against the polygon network before optimization and for three optimized polygon networks. The mean directional vector of the dikes in the three optimized realizations are 71.90, 71.11, and 72.30 respectively, which is much closer to 77.57 of the reference mean directional vector than the 26.70 of the un-optimized Voronoi polygon network. From the plots shown in Figure 8, it can be seen that the generated polygon network before optimization shows a non-uniform distribution. The corresponding raw data histogram and rose diagram (not shown) also verify this observation. The shapes of the length and angle distributions after optimization are much closer to the reference distribution than the distributions were before optimization.

\subsubsection{Post-Processing of the Simulated Polygon Networks}

Real dikes within the polygonal network at Hanford are not perfectly straight and usually show some degree of curvature. To mimic the curvature in the observed dike system, the polygon realization after optimization was post-processed by adding undulations to each simulated dike. The issues considered were the: 1) magnitude of the deviations, and 2) spatial feature of the deviations.

For some statistical analyses of the dikes, e.g., calculation of the length of the dikes and the study of the angular orientation of the dikes, a simplified representation of the dikes was created that "straightened" out the dikes. For the simplified dataset, a representation of the dike used for calculating the orientation and constrained by just two terminal vertices originally may have had more nodes between them. The residual between the curve connecting these intermediate nodes to the straight lines connecting the two terminal vertices of a dike provides general information about the curvature of the real dike system. The histogram and variogram analyses of the residuals provide information on the magnitude of the deviations and the spatial continuity of the deviations, which was then used to modify the simulated dikes by the following procedure.
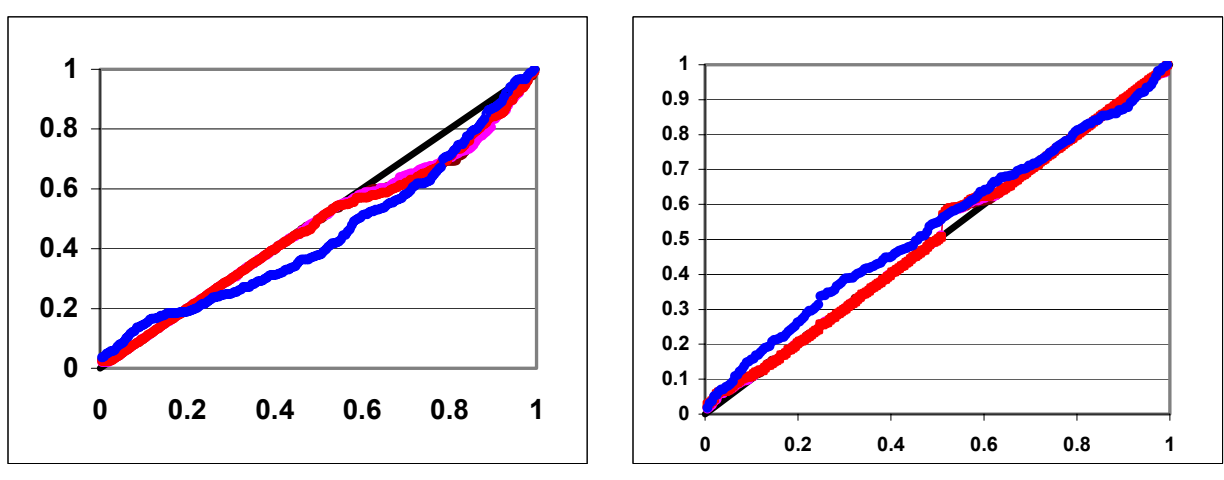

Figure 8. Reproduction of the Length (right) and Angle (left) Distribution. Black: theoretical, blue: before optimization, red/brown/pink: three optimized realizations. 
For each simulated dike, additional intermediate nodes were added between the two terminal vertices. The number of additional nodes added depended on the length of the dike. A length threshold was set and new nodes were not added to any simulated dike shorter than the length threshold. For dikes longer than the length threshold, additional nodes were added on a non-equal distance basis. The dike segments were split into non-equal intervals, and the size of the interval obeyed a user-defined distribution. For instance, a triangular distribution with a mode, min and max limit of interval size was used because there is not enough information to specify the shape of the distribution. The two ending vertices of the dike were used as two control points in the deviation generation, so that the two vertices remained intact in the deviation generation. The deviation for the additional node locations was generated by a random perturbation that follows the distribution of deviation magnitudes found above.

The polygon network after the post-processing consists of an expanded set of vertices (the original set of vertices from optimization plus additional nodes added for each dike segment in this post-processing step), and an expanded set of dike segments. A single polygon edge constrained by the original two vertices now becomes a set of edges constrained by the original two vertices and the additional nodes. Figure 9 shows the results of adding curvature to the simulated dikes. On the left is the polygonal system of the first optimized realization shown in Figure 9, together with an image of the polygonal network after adding deviation. These are preliminary results and only random perturbations have been applied thus far. When there are few additional nodes to be added, adding random deviations does a reasonable job of reproducing the curvature of the dike systems. However, if there are many additional nodes to be added, adding deviation without considering spatial correlation results in non-realistic visual effects of the polygonal system. Future modifications of the post-processing method will examine the possibility of generating the deviations using kriging or stochastic simulation, which will honor the spatial continuity of the deviations from a straight line.

\subsection{Description of Experimental Field Sites}

In 2000, the project used remote sensing and ground-penetrating radar surveys to describe the large-scale distribution of the clastic dikes along Army Loop Road in the 600 Area and at the 216-S-16 pond (Figure 1), where clastic dikes are exposed at the surface. The S-16 Pond site is located approximately $2.5 \mathrm{~km}$ southwest of the southwest corner of the 200 West Area, while the Army Loop Road site is located approximately 5-6 km south of the 200 East Area.
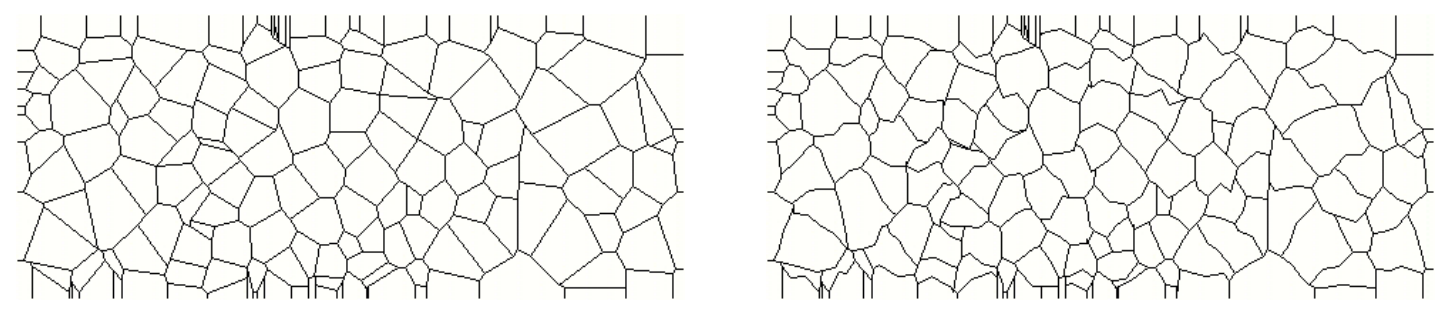

Figure 9. Polygonal Network Before (left) and After Adding Random Deviations to the Simulated Clastic Dikes 


\subsubsection{S-16 Pond Site}

The ground-penetrating radar survey and the air photo and field mapping were used to select a site to trench across a clastic dike. In August 2000, a clastic dike at the 216-S-16 pond was trenched with a backhoe to a depth of $\sim 3.5$ meters (Figure 10). The exposed clastic dike is in the sand-dominated facies of the Hanford formation. The dike is $\sim 0.7 \mathrm{~m}$ thick at the bottom of the trench but becomes extremely narrow $(\sim 8$ to $10 \mathrm{~cm})$ within $\sim 1 \mathrm{~m}$ of the surface. The narrow portion of the dike appears to be a reactivation of the dike along an older dike surface. In the exposures made by the lower two lifts, the host material is very different on each side of the dike (see Figure 10). The material to the west of the dike (to the left in Figure 10) is medium to coarse-grained laminated sand containing some silt and sand rip-up clasts. The material to the east of the dike consists of finer grained, silty fine to medium sand. In addition, a clastic sill (a structure similar to a clastic dike but concordant with horizontal bedding) is exposed east of the dike, near the base of the trench. The sill is seen in Figure 10 as the $\sim 8$-cm-thick, fine-grained unit to the right of the dike in the lower part of the trench. The trench was dug in four lifts. After each lift, except the first, the dike and host sediment were characterized by air permeability measurements and infrared imagining. In addition, samples were taken for moisture analyses, grain size distribution, and mineralogy (X-ray diffraction). A preliminary infiltration experiment was also performed after completion of the S-16 Pond excavation.

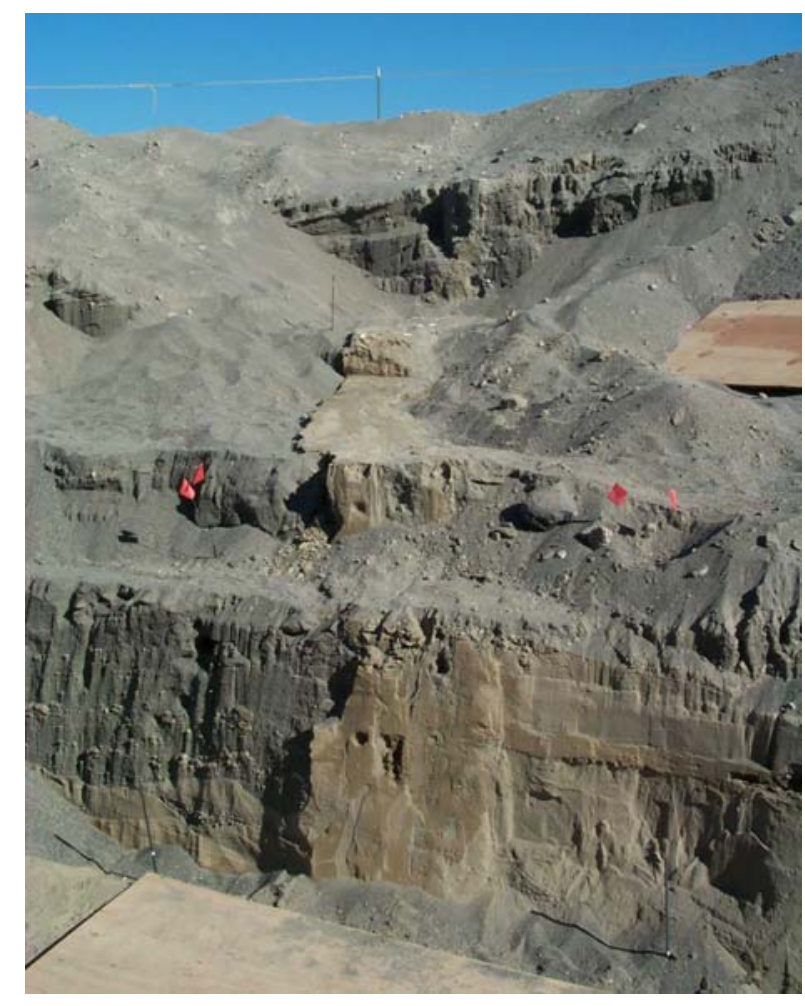

Figure 10. Clastic Dike Exposed in S-16 Pond Excavation. Section of dike exposed on lowest face is approximately $0.7 \mathrm{~m}$ wide. 


\subsubsection{Army Loop Road Site}

In 2001, the project extended its study of the small-scale hydrogeologic properties of clastic dikes. The main focus of the project was on a site near Army Loop Road (Figure 1) that had initially been surveyed using ground-penetrating radar in 2000. The ground-penetrating radar survey and the air photo and field mapping were used to select a site to trench across a clastic dike. In June 2001, a clastic dike at the Army Loop Road site was trenched with a backhoe to a depth of $\sim 3.5 \mathrm{~m}$. The exposed clastic dike is in the sand-dominated facies of the Hanford formation. The dike excavated at the Army Loop Road site was much thicker than the dike excavated in 2000 at the S-16 Pond site ( 2 vs. $0.7 \mathrm{~m})$.

The dike was excavated in three different levels, each approximately a meter high. After the excavation of each level, the slopes surrounding the excavation were pushed back, and the excavation was taken down another level. In this way, we were able to record images of the excavation faces and measure the properties of cross-sections of the dike and matrix at three different levels, which were approximately one on top of the other, without creating a safety hazard in the unstable sediment. The face exposed at each level was mapped, and sediment samples were taken for laboratory analysis. We captured images of each face using an infrared (IR) camera and a digital 35-mm camera, then made a large number of air permeability measurements.

A heavily instrumented infiltration experiment was performed at the Army Loop Road site, immediately adjacent to the excavation. Prior to the installation of the infiltration experiment, Applied Research Associates, Inc., installed eight borehole access tubes at the Army Loop Road site using cone penetrometer (CPT) technology (Figure 11). The access tubes had an inner diameter of approximately $5.1 \mathrm{~cm}$, and ranged from 5.5 to $8.4 \mathrm{~m}$ deep. Each well location was inserted into the ground with an instrumented probe that provides several measures as a function of depth, including the vertical stress on the CPT tip, frictional stress on the side of the probe, pore water pressure, volumetric soil moisture, and soil resistivity. The borehole access tubes were later used to conduct crosshole ground penetrating radar (GPR) tomography and neutron probe logging.

\subsection{Measurement of Geological and Hydrogeological Properties}

A number of methods were used to measure geological and hydrogeological properties of the clastic dikes and enclosing matrix sediment of the Hanford formation. Techniques employed include air permeability, infrared IR imagery, measurement of grain size distributions, moisture contents, x-ray diffraction (XRD) measurements of the mineralogy, GPR, neutron probe log, time-domain reflectometry (TDR), and tensiometers.

We used an air minipermeameter system (Tidwell and Wilson 1997) to measure the air permeability of clastic dike and matrix sediments exposed in the excavations at the S-16 Pond site and the Army Loop Road site. Members of the project team at New Mexico Tech made substantial improvements to the air minipermeameter system. The standard LSAMP II air minipermeameter developed by New Mexico Tech has a practical range of $\sim 9.7 \times 10-04$ to $4.9 \times 10-06 \mathrm{~m} / \mathrm{sec}$, corresponding to fine to medium sand. Investigators from New Mexico Tech modified the system so that it could be used to make measurements in some of the finer-grained sediments present in the clastic dikes. 


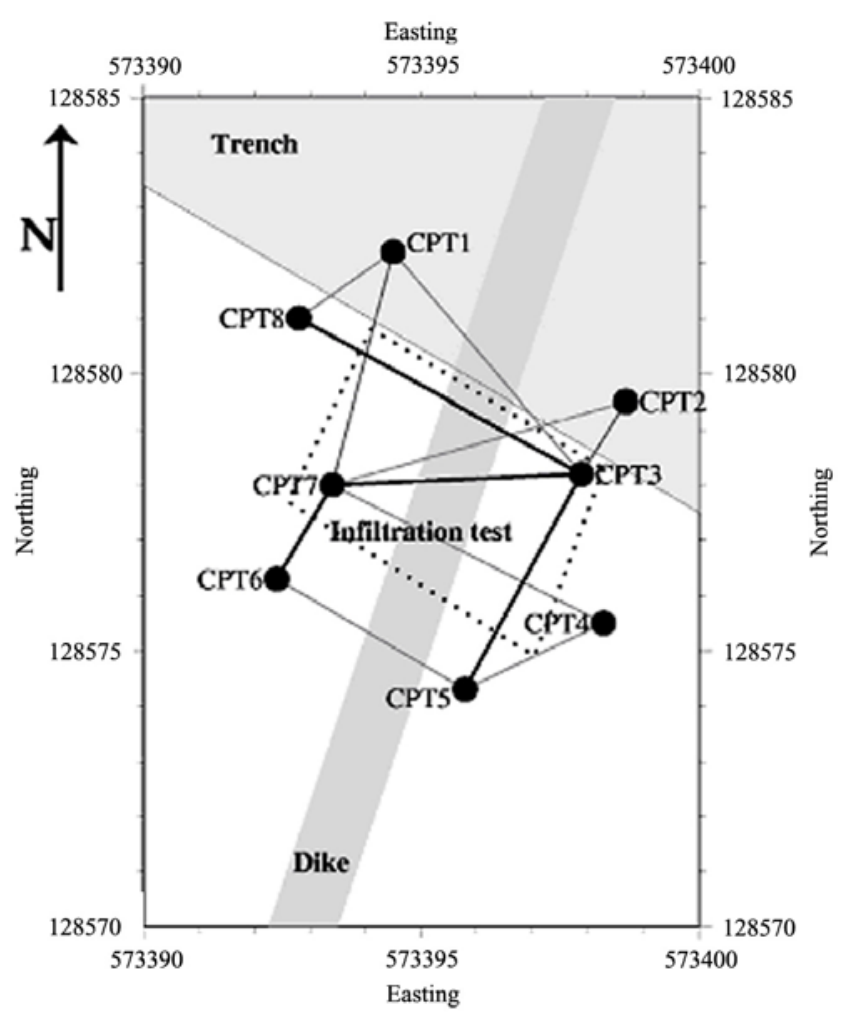

Figure 11. Layout of the Infiltration Experiment and Excavation at the Army Loop Road Site. Monitoring borehole locations are labeled. The area of infiltration is within the dashed rectangle. The surface expression of the clastic dike runs south-southwest to northnortheast.

Saturated hydraulic conductivity, $\mathrm{K}_{\mathrm{s}}$, was measured using the Guelph Permeameter (Reynolds and Elrick 1985) and by mini-disk infiltrometer (Zhang 1997). Mini-disk infiltrometer estimates of $\mathrm{K}_{\mathrm{s}}$ were converted to intrinsic permeability, $\mathrm{k}_{\mathrm{w}}$, to allow comparison with air permeability measurements. Air permeability, $\mathrm{k}_{\mathrm{a}}$, measurements were conducted using a mini-air permeameter.

Long et al. (1996) have successfully applied imaging techniques using IR wavelengths to map detailed permeability distributions in porous media at outcrop scales (resolution in the millimeter range). Infrared and digital photographic images were collected under ambient light conditions in both excavations, and the IR response was correlated to independent observations of permeability collected using the air minipermeameter.

Surface $100 \mathrm{MHz}$ GPR surveys were conducted at three areas: square grid surveys were conducted at the Army Loop Road site and at the 216-S-16 pond, and measurements were made on a $6.9 \mathrm{~km}$ traverse in the 600 Area (see Figure 1). The data were recorded with a PulseEkko 100 GPR unit using $100 \mathrm{MHz}$ and $200 \mathrm{MHz}$ antennas and a 400 volt transmitter. At both sites, a series of lines were recorded perpendicular to the main clastic dike that was later excavated at the site. The lines were spaced $2 \mathrm{~m}$ apart, and data were collected along the line with $0.1 \mathrm{~m}$ spacing. Data on the $6.9 \mathrm{~km}$ traverse were recorded with an approximate spacing of $0.1 \mathrm{~m}$. 
Crosshole GPR tomography was used to map two-dimensional velocity changes between pairs of wells during the 2001 infiltration experiment at the Army Loop Road site. This method has been successfully applied to monitor moisture changes during infiltration tests (Alumbaugh et al. 2002). Radar tomography employs a transmitter in one well and a receiver in the other well. By repeatedly moving both the transmitter and receiver, this geometry enables radar energy to repeatedly sample the space between the wells. Interpretation of the velocity tomogram consists of a forward modeling step and an inversion routine to derive the velocities between the two wells. The velocity data were transformed to estimates of the dielectric constant using a constant radar velocity in air. The moisture distribution between the pair of wells was then estimated from the dielectric constant using Topp's equation (Topp et al. 1980). Data were recorded between several pairs of wells on three dates, prior to the start of the injection on May 1420 , at the end of the injection period on June 12-14, and several months after the end of the injection on September 17-18.

Bulk samples were collected from the trench faces and analyzed for mineralogy, water content, water retention, particle size distribution, and particle density. The mineralogy of the whole rock and clay size fractions of selected sediment samples was also determined by XRD techniques. All samples were analyzed on a Scintag XRD unit equipped with a Pelter thermoelectrically cooled detector and a copper x-ray tube. Semi quantification of mineral phases in the whole rock sediment samples were determined by the whole pattern fitting technique provided by $\mathrm{JADE}^{\circledR}$ XRD pattern processing software.

Particle size analyses were conducted on the $<2 \mathrm{~mm}$ size fraction using a combination of sieving and hydrometer techniques (Gee and Bauder 1986). Dry sieving was performed using sieves with openings of: $2,1,0.5,0.25,0.106,0.075$, and $0.053 \mathrm{~mm}$ with final collection in the pan. Silt- and clay-size fractions were determined by hydrometer. Particle density was also performed on the $<2 \mathrm{~mm}$ size fraction using the pycnometer method (Blake and Hartge 1986). Bulk density measurements were conducted on undisturbed samples using the clod method, and porosity was estimated using the bulk density of undisturbed samples and the average particle density as $\phi=1-\rho_{\mathrm{b}} / \rho_{\mathrm{s}}$.

\subsubsection{S-16 Pond Site}

Figure 12 shows two composite photographs of the lowest level in the trench at the S-16 Pond site. The lower photo is a normal photograph, and the upper photo is infrared. The contrast in the infrared photo is due to variation in the moisture content of the sediment; darker colors indicate more moisture. The dark vertical band on the left side of the infrared photo is the clastic dike, and the dark horizontal band is the clastic sill. Several hundred air permeability measurements were obtained from the exposures in the trench. Figure 13 shows the distribution of the air permeability results. The dike and sill exposed in the trench tend to be finer-grained than the host material, and therefore, have a higher moisture content and lower permeability than the host material. Figure 14 shows a box plot comparing the moisture content in the dike and host materials.

Samples were collected from the dike and host sediment to compare the mineralogy and grain size distribution between the dike and host sediment. Qualitative X-ray diffraction analysis of 21 samples showed that the mineral composition of both the dike and the host sediment is dominated by quartz and plagioclase feldspar. Lesser amounts of pyroxene, mica, chlorite, and amphibole are also present in most samples. Calcite was identified in only three samples. No apparent differences were found in the mineral 


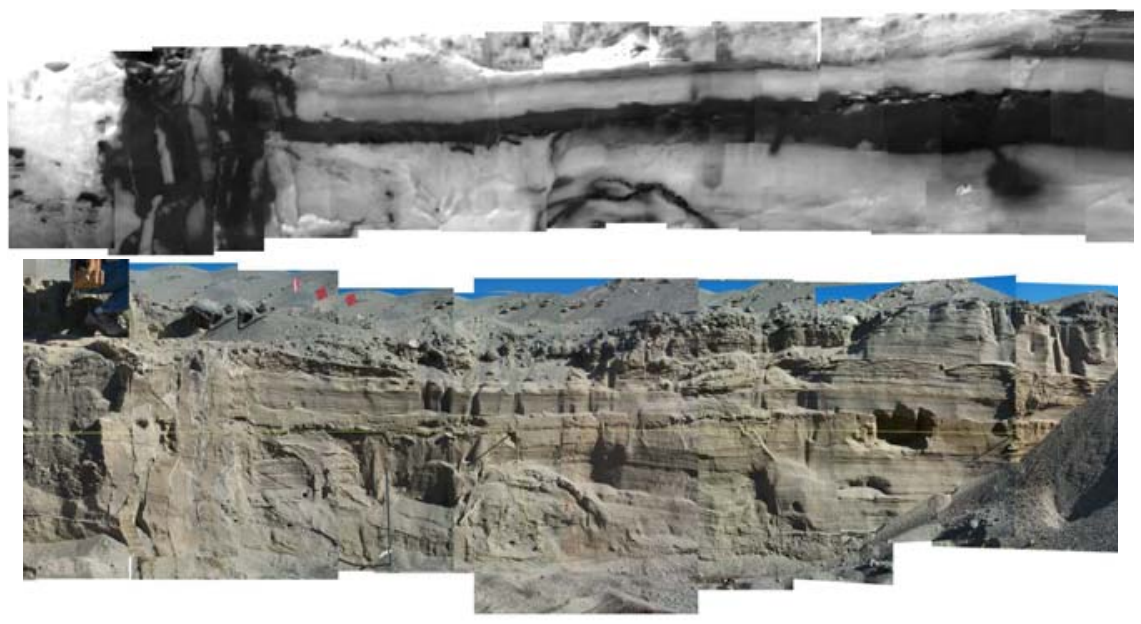

Figure 12. Comparison of IR (top) and Visible (bottom) Images of Lowest Tier of S-16 Pond Excavation

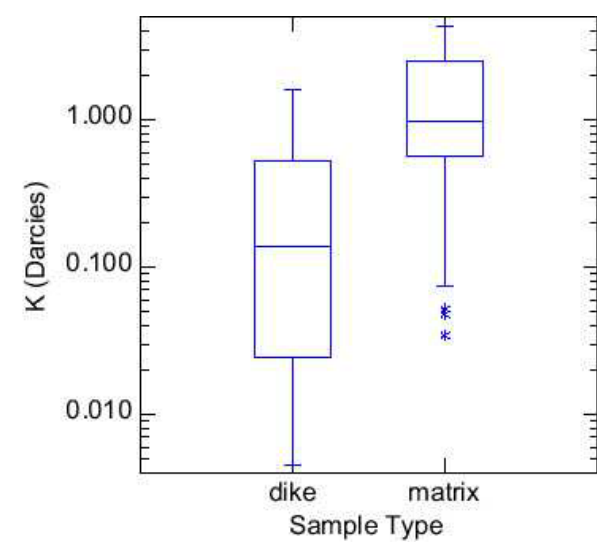

Figure 13. Air Permeability Results from S-16 Pond Excavation

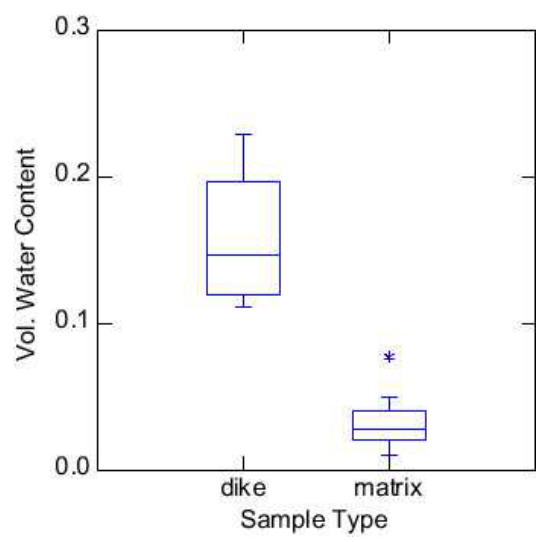

Figure 14. Moisture Contents of Dike and Matrix at S-16 Pond Site 
composition between the dike and host sediment. Nineteen samples were submitted for analysis of particle size distribution. In general, the samples from the dike tend to be much finer grained than do samples of host sediment.

\subsubsection{Army Loop Road Site}

We employed two air minipermeameters during the fieldwork at the Army Loop Road site — a standard instrument and one with an extended range that allowed us to measure finer-grained material. This allowed us to make substantially more measurements in 2001 than during the previous year. We took a total of about 450 measurements on the three tiers, one-third in the dike and two thirds in the matrix. Similar to what we found at the S-16 Pond site, the results indicate the median air permeability of the dike is about an order of magnitude lower than the permeability in the matrix. The variability of the data from the dike is much higher than that of the matrix, with a coefficient of variation (i.e., ratio of standard deviation to the mean) of 1.2 in the dike vs. 0.6 in the matrix. The overall variability of air permeability in the dike-matrix system is about four orders of magnitude (Figure 15). This is an important observation, because some methods used for upscaling permeability data assume the variability in the system is low, about an order of magnitude, which means it would be questionable to apply those methods to the clastic dike and its surrounding sediments.

We made an effort at the Army Loop Road excavation to estimate the continuity of the vertical bands seen within the clastic dike. A transect was laid out on the floor of the middle layer of the excavation on a horizontal exposure of the dike. Each band encountered in the transect was then traced up and down the excavation to see if it was continuous. The measured continuity is the total trace of one band along each vertical face and across the horizontal exposures (the "floors" of the excavation) linking the vertical faces. So the measured continuity is a combination of both vertical and horizontal continuity within the 2.5dimensional excavation. The vertical bands that were measured did not include the very thin and very fine-grained clay and silt skins (usually less than $1 \mathrm{~cm}$ thick) associated with the major bands. The clastic

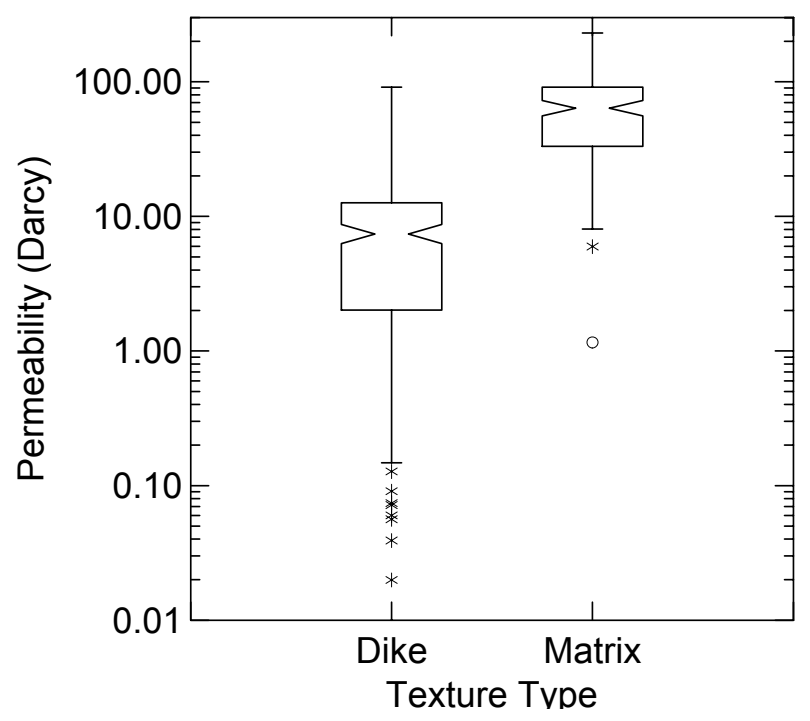

Figure 15. Air Permeability Measurements from Army Loop Road Excavation 
dike bands that were characterized had a median thickness of $5 \mathrm{~cm}$ and ranged from 2.5 to $14 \mathrm{~cm}$. In most cases, the bands could be traced for about $1.6 \mathrm{~m}$ before they pinched out or were obstructed by a clay/silt skin cutting across the band. The range of continuity observed was from 0.2 to $7.7 \mathrm{~m}$, with all but one of the bands having an apparent continuity of less than about $2.5 \mathrm{~m}$. This degree of continuity will affect transport through the clastic dike and will be used to help determine the likelihood of long range transport of material through clastic dikes.

\subsection{Field Infiltration Experiments}

\subsubsection{Infiltration Experiments at S-16 Pond Site}

In addition to the hydraulic tests described above, drip-irrigation and dye-tracer studies were done at the excavation. Vertical time-domain reflectometry probes, $0.25 \mathrm{~m}$ long, were driven into the exposed horizontal face at $0.15 \mathrm{~m}$ back from the exposed vertical face. These probes were spaced every $0.3 \mathrm{~m}$ along the traverse. Horizontal probes, $0.5 \mathrm{~m}$ long, were driven into the exposed vertical face in a grid with spacings of $0.3 \mathrm{~m}$ horizontally and $0.15 \mathrm{~m}$ vertically. A drip irrigation system with lines spaced $\sim 5 \mathrm{~cm}$ apart was used to uniformly deliver known amounts of water. Several parameters were measured during the experiment. Volumetric water content was monitored along the surface and the cut face. Soilwater pressure head was monitored with tensiometers along the bench surface and field-saturated conductivity was measured every $0.15 \mathrm{~m}$ along the bench surface using a tension infiltrometer. In addition, soil samples were collected on a $15-\mathrm{x} 15-\mathrm{cm}$ grid on the cut face to analyze for particle-size distribution.

Five injections of water were applied, totaling $738 \mathrm{~L}$. Figure 16 shows the distribution of soil moisture 3 days after the first injection. The figure shows that the wetting front appears deeper in the dike than in the relatively coarser-grained host sediment. This is, in part, due to capillary wicking of the finer sediment in the dike. The water was applied so that the soil remained unsaturated; therefore, capillary wicking was quite important. After nearly a week, the entire exposed face on the west of the dike was visibly wet to a depth of greater than $1 \mathrm{~m}$, while on the east side the sediment appeared to be uniformly wet to a depth of $\sim 75 \mathrm{~cm}$, or $\sim 20 \mathrm{~cm}$ below the bottom of the horizontal clastic sill.

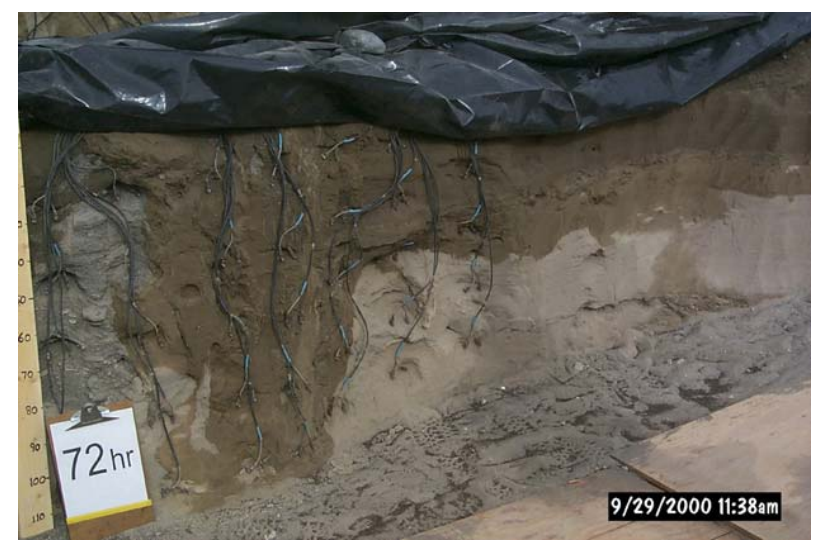

Figure 16. Distribution of Soil Moisture Three Days After Initial Infiltration 


\subsubsection{Infiltration Experiments at Army Loop Road Site}

A large-scale infiltration experiment was conducted at the Army Loop Road site in 2001. A drip irrigation system was used to apply the specified fluxes. The application area was centered on the dike and aligned with the longer axis perpendicular to the dike. Three fluxes of water were applied to the clastic dike and surrounding matrix, and the progress of the infiltrating water was monitored for each flux rate. Water content, matric potential, and electrical conductivity were measured throughout the tests using a neutron probe, cross-borehole radar, tensiometers, and TDR probes. The TDR probes and tensiometers were installed to a depth of $0.5 \mathrm{~m}$ on a transect oriented perpendicular to the dike.

The three fluxes applied were $0.001,0.01$, and $0.1 K_{s}$ of the host matrix, in that order. For typical soils, this translates roughly into flux values of, $10^{-5}, 10^{-4}$, and $10^{-3} \mathrm{~cm} / \mathrm{s}$. Similar fluxes have been used in previous field tests of surface soils at the Hanford Site (see Khaleel 1999, Appendix C). These fluxes are a compromise between the length of time it would take to run an experiment at input fluxes representative of Hanford recharge conditions (10-100 $\mathrm{mm} \mathrm{yr}^{-1}$ or $3.16910^{-8}$ to $3.16910^{-7} \mathrm{~cm} \mathrm{~s}^{-1}$ ) and project time constraints. Nevertheless, the resulting data were expected to provide insight into flow and transport phenomenology and its dependence on the underlying heterogeneity. Relating each flux to the resulting equilibrium water content provided a measure of the unsaturated conductivity function (Youngs 1964). The water content and matric potential data provide a direct measure of in situ water retention.

Once steady state was achieved with the third (and highest) flux rate, the irrigation supply tank was switched to a solution of $\mathrm{KBr}$ and Brilliant Blue FCF dye. The effect of $\mathrm{KBr}$ on the electrical impedance of the soil allowed tracking of solute movement and the construction of solute breakthrough curves. Irrigation was continued until the $\mathrm{KBr}$ moved below the TDR sensing zone (about $0.5 \mathrm{~m}$ ). Further movement of the water was monitored with neutron probe and cross-borehole radar measurements.

The excavation began after the application of the tracer in the infiltration area. The main excavation face was approximately 8 -to $10 \mathrm{~m}$ from the edge of the infiltration zone, so that the moisture would not affect the air permeability measurements or IR imaging. However, after construction of the main excavation area was complete, an additional face was cut at the edge of the infiltration area so the distribution of the tracers could be examined. The upper portion of Figure 17 shows a composite color photographic image of what we termed the "dye" face, with the lower portion of the figure being a map of the moisture distribution in the face. The photographic image shows the very heterogeneous distribution of the blue dye. The dike is in the center-right area of the image, from 3 to $5 \mathrm{~m}$, which was at a higher moisture content also appear to transmit less dye. However, some of the deepest penetrations of the dye occur in restricted bands within the dike, which coincide with regions of coarser texture (Figure 17).

The map of the moisture distribution in the lower portion of Figure 17 was made using TDR probe measurements on a $20-\mathrm{cm}$ horizontal and $10-\mathrm{cm}$ vertical grid across the entire face. The moisture map captures the main features of moisture distributions seen in the photographic image and highlights a fundamental characteristic of flow in heterogeneous unsaturated porous media. In heterogeneous systems, there can exist complimentary transport domains that depend on saturation. In this case, there are two complimentary domains: 1) a fine-textured, high permeability domain active at relatively low fluxes when $K(\theta)$ of these regions exceed that of the host matrix, and 2) a coarse-textured, high-permeability 

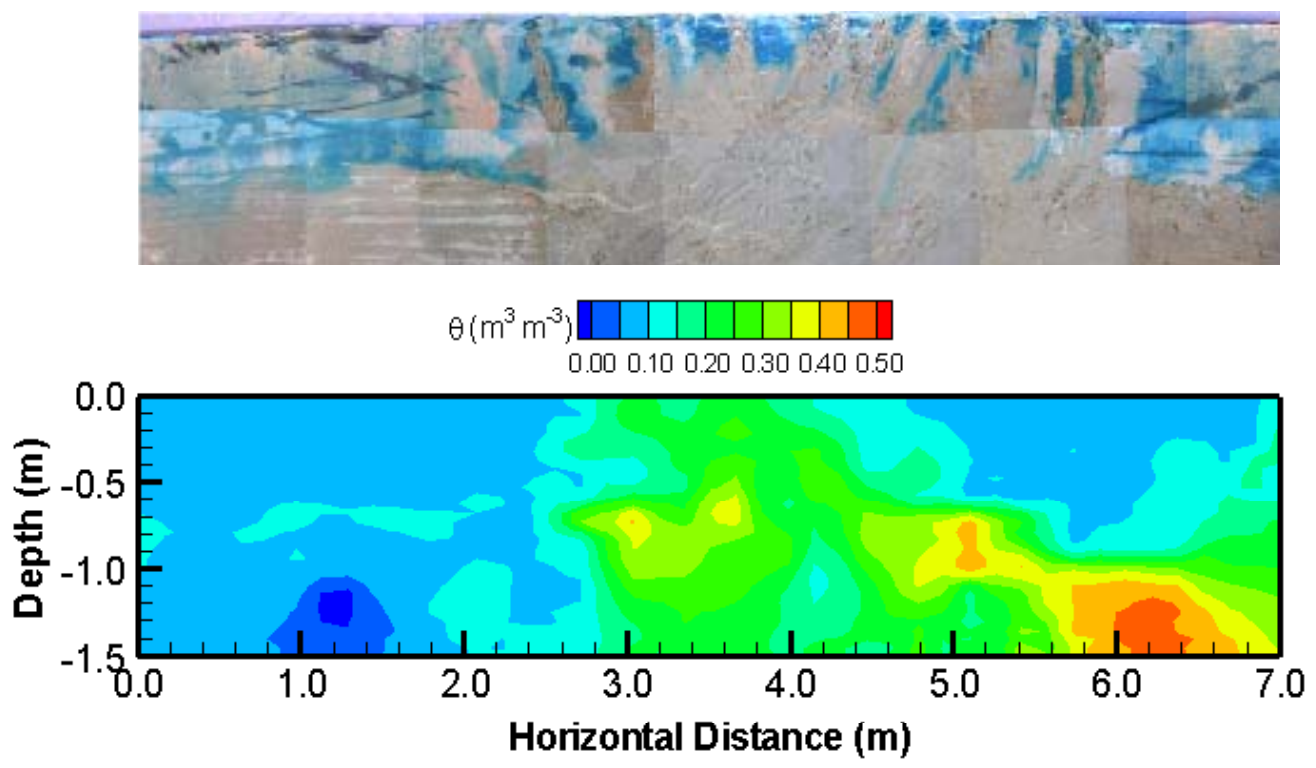

Figure 17. Top - Composite Image of Dye Penetration. Bottom - Contour Map of Clastic Dike. Water content measurements for surface are shown in upper image.

region that is active at high fluxes when $\mathrm{K}(\theta)$ of the host matrix exceeds that of the dike. These complimentary flow domains can mask the underlying heterogeneity as water is redirected around regions of different texture, depending on flux and saturation. Nevertheless, it appears that dikes could very well enhance vertical flow, but only under very specific flux conditions. These results also highlight another difficulty and that is the ability to monitor flow and transport over the multiple scales of heterogeneity that appear to control flow.

We used tomographic GPR to map the distribution of moisture between pairs of boreholes as the infiltration experiment progressed. Horizontal and vertical resolution of the data is $0.1 \mathrm{~m}$. We took measurements immediately prior to the start of the infiltration experiment near the end of May; immediately after the infiltration had ceased in mid-June; and several months afterward to estimate the redistribution of the moisture with time. The radar tomography successfully estimated the changing moisture distribution for pairs of boreholes that were on the same side of the clastic dike, but was unable to image the dike itself when the dike was located between the pair of boreholes. This may be due to the near-vertical orientation of the dike and the high radar attenuation potential of the material within the dike.

\subsection{Modeling of Field Infiltration Experiments at the Army Loop Road Site}

\subsubsection{Geologic Interpretation for Model Development}

A combination of particle size analysis and digital photogrammetry was used to build a $2 \mathrm{D}$ geologic model of the outcrop in a five-step procedure. In the first step, high-resolution digital visible and infrared images were compiled into a mosaic with a resolution of $0.111 \mathrm{~cm}$ per pixel. Air and intrinsic permeabilities measured in the field were assigned to their spatial locations on the mosaic. 
We found that the IR data and the air permeability data collected from the dike and surrounding matrix at the Army Loop Road are positively correlated with one another, with a linear correlation coefficient of 0.73 (Figure 18). This analysis was performed on a normal score transform (Deutsch and Journel 1998) of the data. Variogram analysis of the normal scores of the two datasets indicated that the spatial continuity of the air permeability and IR data were very similar.

Particle size distributions derived from the outcrop samples were also assigned to corresponding locations on the mosaic. We constructed scatter plots of IR temperatures, air permeability, and intrinsic permeability versus geometric mean grain diameter and determined the correlations between the variables. The relationship between IR temperature and air permeability was used to predict the permeability for the entire domain based on infrared temperature and texture segmentation based on digital photogrammetry (Figure 19). The cooler temperatures in Figure 19b represent areas of higher moisture content, which are mostly regions occupied by silt and silt loam. These soils are the most permeable soils in the vadose zone under the ambient, low recharge conditions present at the Hanford Site. Sediment types were differentiated by texture based on the content of sand, silt, and clay according to the U.S. Department of Agriculture (USDA) textural triangle.

Figure 20 shows a log-probability plot of particle diameter, $d$, as a function of cumulative mass percent less than $d$. The wide range of textures exemplifies the variability at the field site. Even though these samples were all from material that is from the sand dominated upper Hanford formation, or appears to be derived from that material, there were many samples with size distributions reflecting a finer texture relative than the typical Hanford sand. Soil textures, derived from the ratio of sand, silt, and clay, ranged from coarse sands (AL-HT2-1) with over 95\% sand for matrix sample, to medium and fine sands (AL-CDT2-2) in coarse segments of the clastic dike, to loam and silt loam (AL-CD-T2-7) with as much as $19 \%$ clay in the fine-grained portions of the clastic dike. This wide variation in particle size distribution can be expected to influence water retention characteristics and permeability, and ultimately, the flow and transport properties under unsaturated conditions.

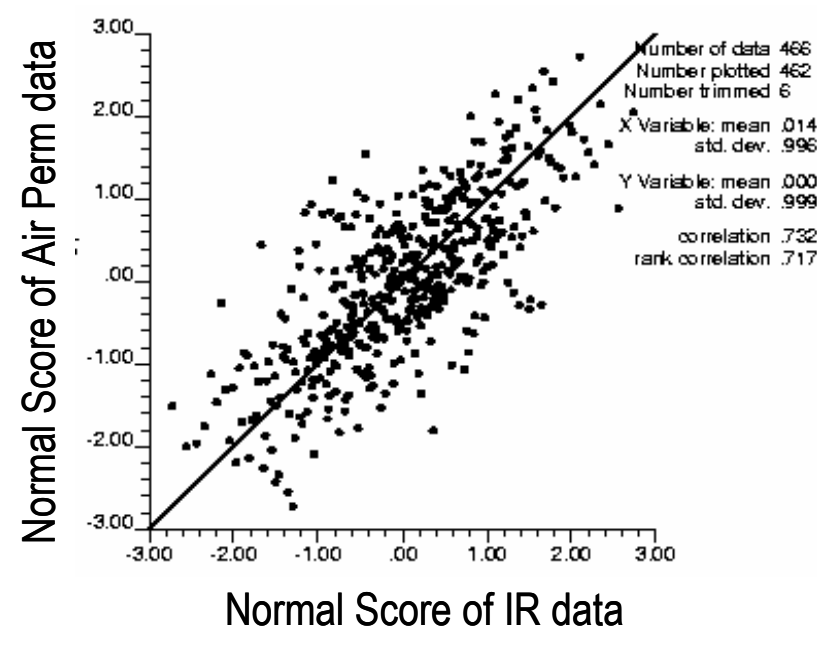

Figure 18. Cross Plot of Air Permeability Data and IR Data 


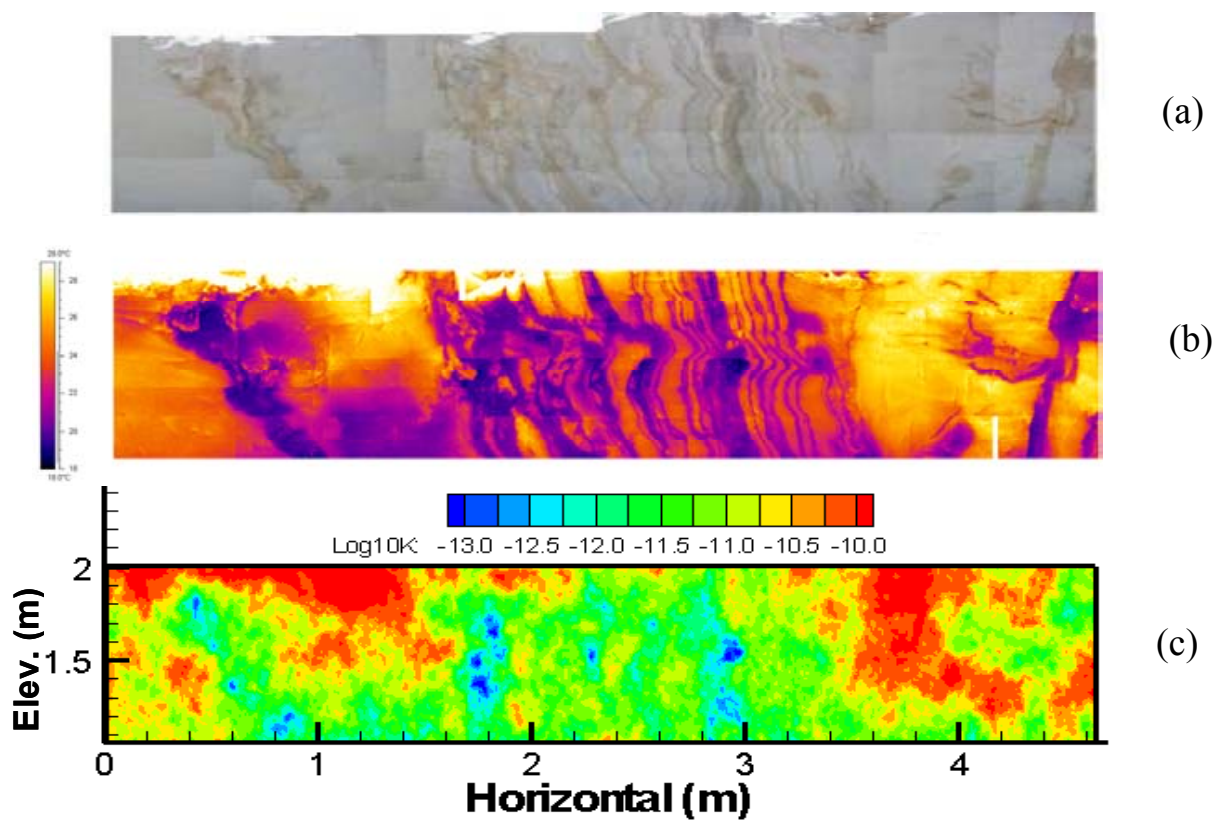

Figure 19. Spatial Variability at Tier 2 Outcrop (a) the top image shows spatial variation in soil textures, (b) shows measured infrared temperatures, and (c) shows vertical saturated hydraulic conductivity, inferred from the relationship between geometric mean grain size and intrinsic permeability.

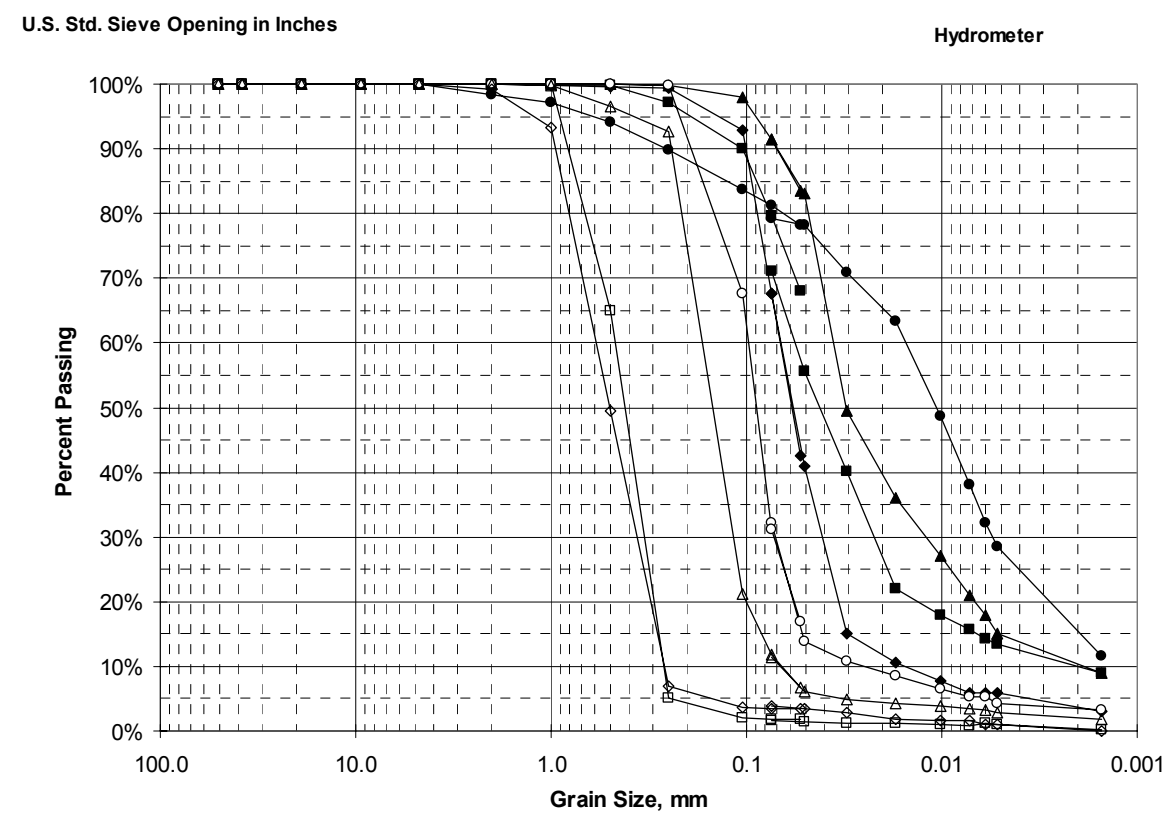

Figure 20. Geographical Comparison of Particle Size Distribution from $<\mathbf{2} \mathbf{~ m m ~ F r a c t i o n s ~ f r o m ~ t h e ~}$ Army Loop Road Field Site. Essentially five entries were identified from the analysessilt loam (e.g., IN-A1-5, •), loam (e.g., AL-CD-T3-1, ø); sandy loam (e.g., AL-CD-T2-8, •); loamy sand (e.g., AL-CDT2-5, ○); and sand (e.g., Al-HT4-1, $\square$ ). 


\subsubsection{Simulation of Water Flow}

The water operational mode of the STOMP (Subsurface Over Multiple Phases) simulator was used to simulate water flow. The STOMP simulator is a 3D, fully implicit, integrated finite difference code that has been used to simulate a variety of multiphase (White and Oostrom 2000; Oostrom and Lenhard 1998) and variably saturated flow systems (Ward et al. 1997; Rockhold et al. 1999; Zhang et al. 2002, 2003). This simulation mode assumes the porous medium to be incompressible, and fluid properties are assumed to be time invariant. The governing partial differential equation was discretized following the integratedvolume finite difference method by integrating over a control volume. Using backward Euler time differencing to yield a fully implicit scheme, a series of nonlinear algebraic expressions was derived. The algebraic forms of the nonlinear governing equations were solved with a multivariable, residual-based Newton-Raphson iterative technique. In this series of simulations, internodal conductance was computed as the product of the harmonic mean of the saturated permeability in adjacent grid blocks and upgradient averaged relative permeability. Harmonic averaging was used for all other flux components. The maximum number of Newton-Raphson iterations was set to eight, while the tolerance was set at $10^{-6}$.

Water flow was simulated on a 2D vertical outcrop of the dike (Tier 2 of the Army Loop Road excavation), $4.7 \mathrm{~m}$ long and $2 \mathrm{~m}$ deep encompassing the dike and surrounding host matrix (Figure 21). Simulations were performed with either Neumann or Dirichlet conditions at the upper boundary; no flow conditions on the east and west; and a unit gradient condition at the lower boundary.

To represent the local-scale flow and transport heterogeneities, grid resolution must be consistent with the local scale processes. Thus, node spacing was uniform and ranged from $0.111 \mathrm{~cm}$ in a micro-scale model of only the dike region to as much as $10 \mathrm{~cm}$ in the coarsest upscaled model of the entire outcrop. The total number of nodes in each grid ranged from over 3.5 million nodes in the microscale model of the entire transect to 8600 in the coarsest upscaled model. Seven cases were simulated with fluxes ranging from $0.1 \mathrm{~mm} \mathrm{yr}^{-1}$ to $10^{5} \mathrm{~mm} \mathrm{yr}^{-1}$ (Table 2). To evaluate the effect of the boundary type of the subsurface flow process, seven cases were simulated in which a Dirichlet condition, $\psi=\psi_{0}$, was imposed on the upper boundary. Subatmospheric potentials were selected to match the steady-state matric potentials at the surface for infiltration under the Neumann condition.

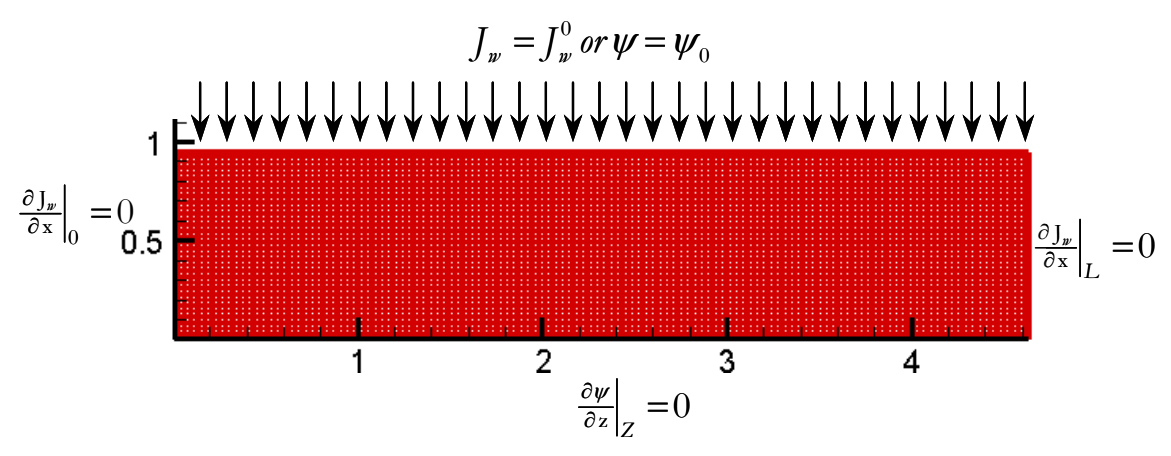

Figure 21. Flow Domain with Boundary Conditions 
Table 2. Summary of Cases Simulated and Boundary Type

\begin{tabular}{|c|c|}
\hline Case & $\begin{array}{c}\text { Neumann Condition } \\
\boldsymbol{J}_{\mathbf{w}}^{0}, \mathbf{m m ~}_{\mathbf{~} \mathbf{r}^{-\mathbf{1}}}\end{array}$ \\
\hline 1 & 0.1 \\
\hline 2 & 1.0 \\
\hline 3 & 10 \\
\hline 4 & $10^{2}$ \\
\hline 5 & $10^{3}$ \\
\hline 6 & $10^{4}$ \\
\hline 7 & $10^{5}$ \\
\hline
\end{tabular}

\subsubsection{Model Parameters}

Secondary variables, i.e., those parameters not directly computed from the solution of the governing equations, were computed from the primary variables through the constitutive relations. In this study, the Brooks-Corey (1964) model was used to represent the relationship between relative permeability, fluid saturation, and capillary pressure (k-s-P). Relative permeabilities were computed as a function of saturation using a modified form of Burdine's (1953) relative permeability model, integrated using the Brooks and Corey (1964) s-P relation.

The values for the key parameters for the moisture retention curve (s-P) and the unsaturated hydraulic conductivity function (k-s-P) were determined for each representative soil based on the particle size distribution and texture classification. The moisture characteristic of a given soil has been shown to be dependent on the pore size distribution, which is in turn related to the proportions of each particle size class and the bulk density (Campbell 1974). Particle size distributions were assumed to be log normally distributed with a geometric mean grain diameter, $d_{g}$, and a geometric standard deviation, $\sigma_{\mathrm{g}}$. These parameters were computed from particle distributions by calculating the contribution of each of the textural fractions sand, silt, and clay. The power of the moisture retention curve (s-P), $\lambda$, and the capillary pressure at air entry or bubbling pressure, $\mathrm{P}_{\mathrm{b}}$, were also estimated from the particle size data according to (Campbell 1974). The saturated water content, $\theta_{\mathrm{s}}$, was estimated as the product of $\phi$ and the effective porosity. Typical values of effective porosity range from 0.80 to 0.95 (Arya et al. 1999). Measured grain size distributions were analyzed to determine geometric parameters defined above and to predict hydraulic properties at unsampled regions of the experimental site. Relationships between $\mathrm{k}_{\mathrm{w}}$, and $\mathrm{k}_{\mathrm{a}}$ were used with $\mathrm{d}_{\mathrm{g}}$ to interpolate $\mathrm{k}_{\mathrm{w}}$. For the microscale model, the hydraulic conductivity field was assumed isotropic at the local scale. However, upscaled conductivities were anisotropic with the upscaling performed using methods recently developed by EMSP Project 70187 ("Quantifying Vadose Zone Flow and Transport Uncertainties Using a Unified, Hierarchical Approach”, Philip Meyer, PI) and described in Rockhold et al. (1999, 2002) and Meyer et al. (2002).

There was a disparity between the scale of measurement and the scale at which the flow domain could be discretized for simulation in a reasonable time. The dimensions of the full domain for the three tiers ranged from $4245 \times 814$ on Tier 1 ( 3.35 million nodes), to $4185 \times 858$ on Tier 2 ( 3.59 million nodes) to $4239 \times 880$ (3.73 million nodes) on Tier 3. The combination of infrared and visible images coupled with 
permeability measurements provided estimates of permeability on a grid on $0.111 \mathrm{~cm}$. Hydraulic conductivity upscaling was therefore necessary to transform the grid of permeabilities at the scale of measurement onto a coarser grid of block permeability tensors. Hydraulic properties were upscaled using a generalization of the method developed by Rockhold et al. $(1999,2002)$ and Meyer et al. (2002).

Figure 22 shows typical water retention curves for the range of textures observed at the outcrop. It is clear that the characteristics derived from the granulometric data capture the essential features of heterogeneous unsaturated soils. These curves show a clear dependence of saturated water content, $\theta_{\mathrm{s}}$, on texture and a dependence of water content, $\theta$, on the matric potential, $\psi$. In general, $\theta$ is higher in the fine-textured silt loam and silts than in coarse-textured sands across the range of matric potentials.

For large negative values of $\psi$ (i.e., large $\log [-\psi]$ ), $\theta$ in the finer sediments can be three times higher than in the coarser sediments. In addition, the range of air entry pressures, $\mathrm{P}_{\mathrm{b}}$, from around $5 \mathrm{~cm}$ for coarse sands to over $60 \mathrm{~cm}$ for silt loam is consistent with laboratory and field measurements. These characteristics will impact the relative permeability functions as shown below.

Figure 23 shows typical hydraulic conductivity functions for the range of textures observed at the outcrop. For small negative values of $\psi$ (i.e., small $\log [-\psi]$ ), at and near saturation, $\mathrm{K}$ of the coarse sediments is higher than that of the finer sediments. The air entry pressure is also lower in the coarse sediments. This relation is reversed as $\psi$ decreases (as $\log [-\psi]$ gets larger). As $\psi$ decreases, large pores empty earlier and the sediment becomes less permeable.

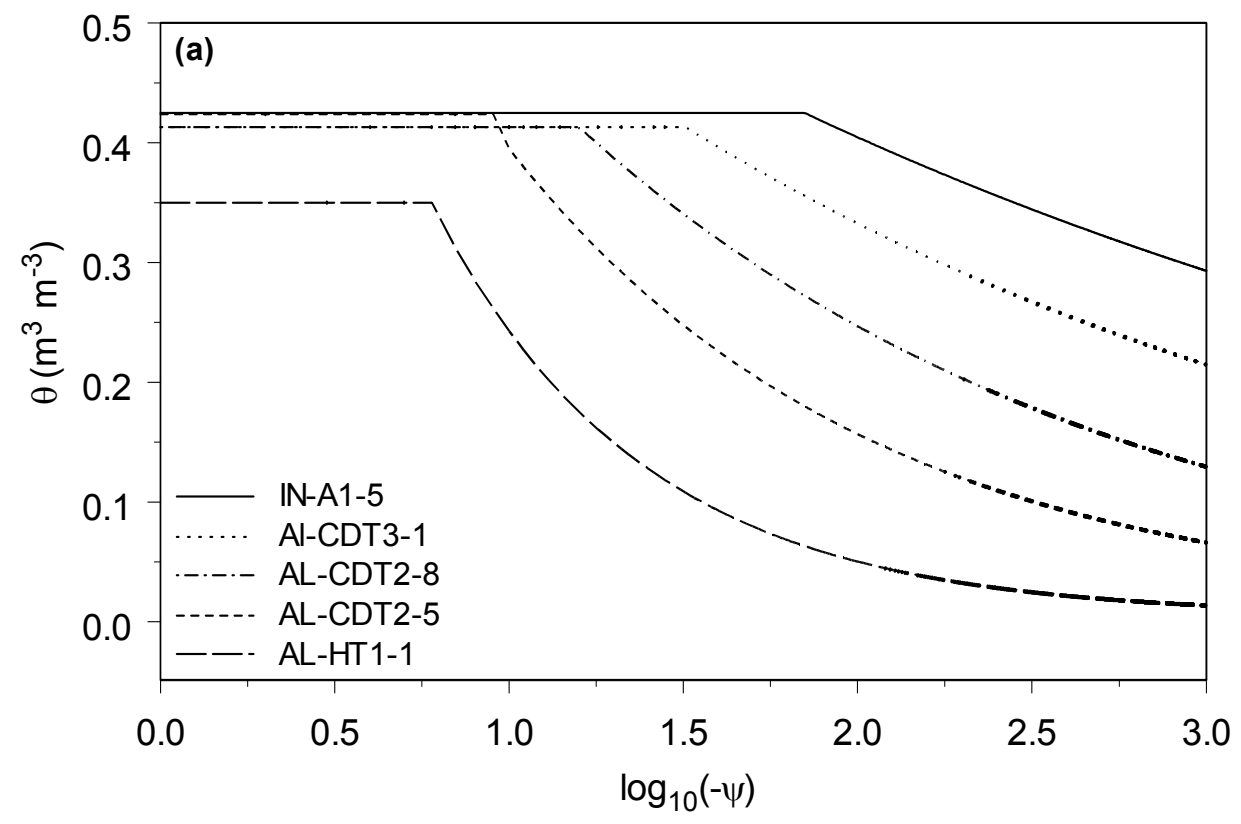

Figure 22. Hydraulic functions for five typical soils from the Army Loop Road Dike Site (a) water retention, $\theta(\psi)$, and (b) hydraulic conductivity, $K(\psi)$. Textures included silt loam (IN-A1-5), loam (AL-CDT3-1), sandy loam (AL-CDT2-8), loamy sand (AL-0CDT2-5) and sand (AL-HT1-1). Matric potential, $\psi$, is in $\mathbf{m}$ and hydraulic conductivity is in $\mathrm{cm} \mathrm{s}^{-1}$. 


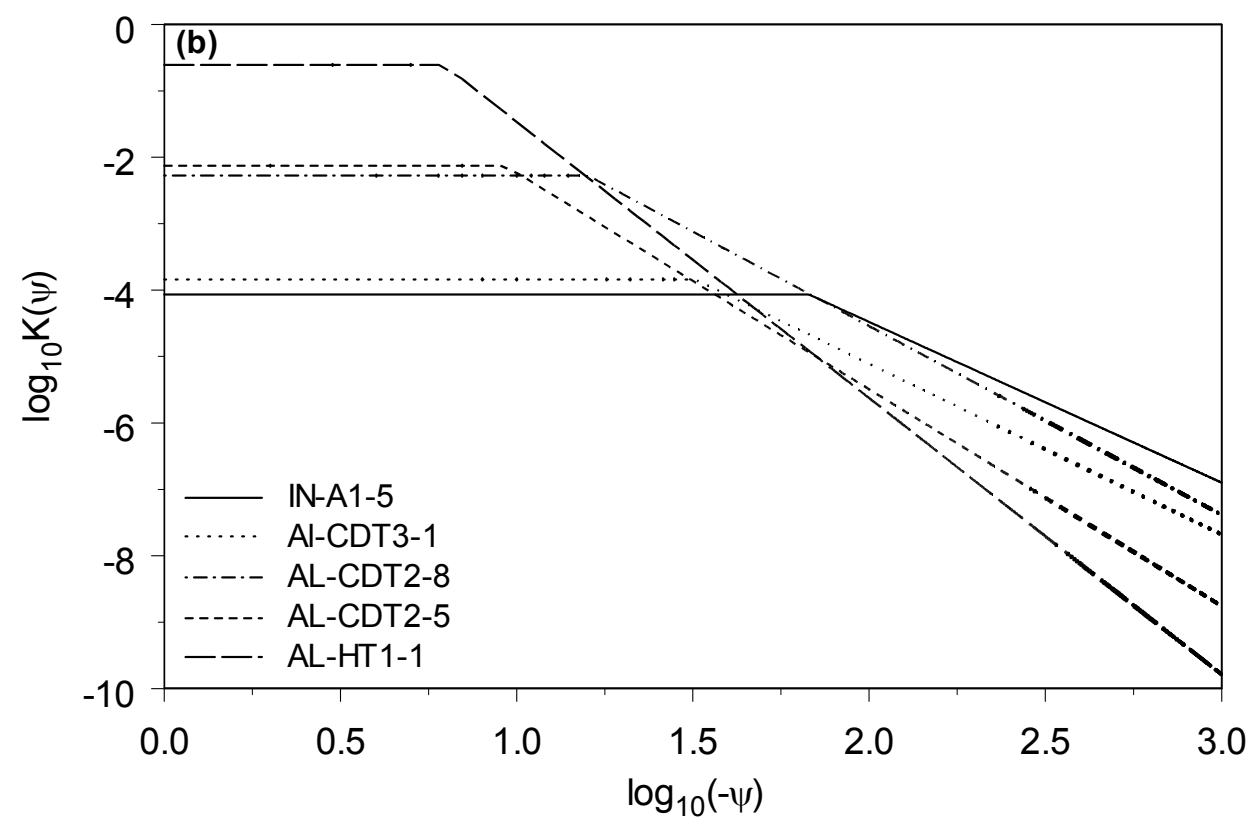

Figure 23. Hydraulic Conductivity Function for Five Typical Soils from the Army Loop Road Dike Site. Textures included silt loam (IN-A1-5), loam (AL-CDT3-1), sandy loam (AL-DT2-8), loamy sand (AL-0CDT2-5), and sand (AL-HT1-1). Matric potential, $\psi$, is in $\mathbf{m}$ of water. Hydraulic conductivity is in $\mathrm{cm} \mathrm{s}^{-1}$, matric potential, $\psi$, is in $\mathbf{m}$ of water.

The higher air entry pressure of the fine-textured sediments cause them to retain water at lower values of $\psi$; consequently, $\mathrm{K}$ of the fine-textured sediments exceeds that of the coarser sediments. It should be noted that there is a value of $\psi$ at which $\mathrm{K}$ for the different textures are equal. Different soils will therefore conduct water at the same rate during constant flux infiltration only if $J_{w}^{0}$ corresponds to the associated value of $\mathrm{K}(\psi)$. This phenomenon is the fundamental difference between unsaturated flow in heterogeneous systems and flow in homogenous or in saturated systems. Under typical field conditions in which flow is transient, this phenomenon will cause flow networks and transport behavior to change with the input flux and even boundary type. Depending on the degree of heterogeneity, flow networks and transport rates will change with saturation, can be equal in different soil textures, and can even alternate between soil textures, depending on the surface flux and boundary type. Owing to the fact that a limited amount of data are typically available for modeling the effects of clastic intrusions across multiple scales, modelers have often resorted to the use of average or effective properties. Such an approach is incapable of reproducing the complex flow patterns observed due to the presence of these features and will lead to erroneous conclusions about the effect of clastic intrusions on field scale transport.

\subsubsection{Subsurface Moisture Patterns and their Relation to Surface Flux}

Figure 24 shows typical subsurface distributions of water content in response to steady input fluxes ranging from $10^{-10} \mathrm{~cm} \mathrm{~s}^{-1}$ to $10^{-5} \mathrm{~cm} \mathrm{~s}^{-1}$. A shown in Figure 19, the flow domain exhibited heterogeneities over a wide range of spatial scales. This heterogeneity is reflected in the distribution of water content, 


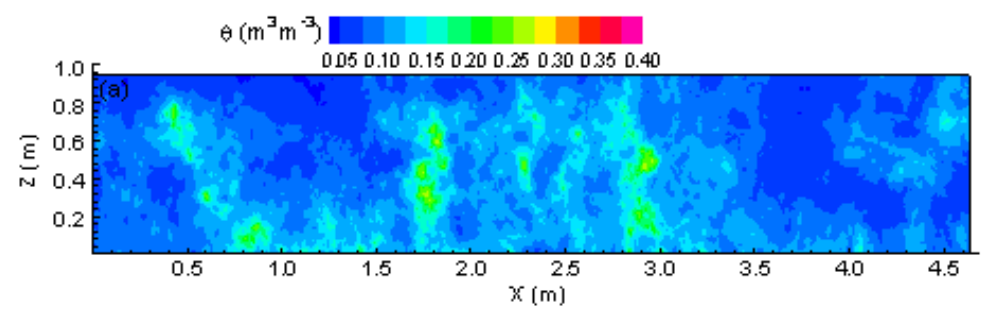

(a)

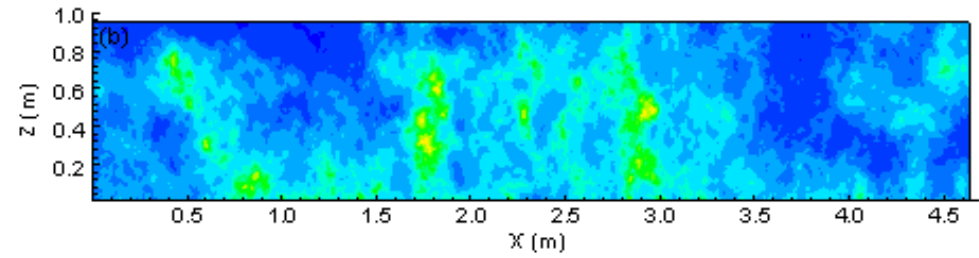

(b)

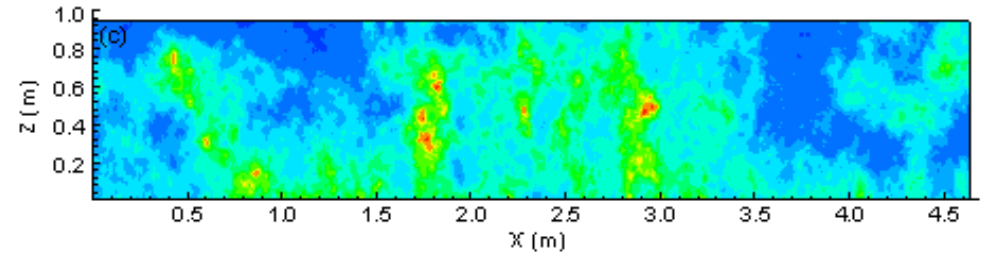

(c)

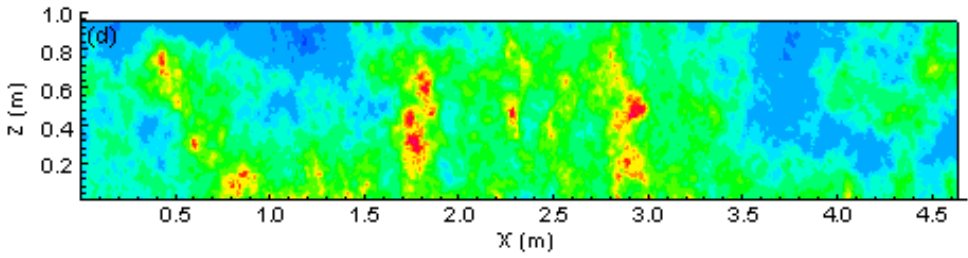

(d)

Figure 24. Distributions of Volumetric Water Content During Steady Infiltration Under a

Constant Surface Flux of (a) $1 \mathrm{~mm} \mathrm{yr}^{-1}$, (b) $10 \mathrm{~mm} \mathrm{yr}^{-1}$, (c) $10^{2} \mathrm{~mm} \mathrm{yr}^{-1}$, and (d) $10^{3} \mathrm{~mm}$ $\mathrm{yr}^{-1}$. Domain properties were upscaled to $2 \mathrm{~cm}$ grid.

$\theta$. Values of $\theta$ vary over the entire range of possible values, even at the lowest flux (Figure 24a). The gradient $\nabla \psi$, together with gravity, is the driving force of the water flux, and this flux will tend to minimize the potential gradients. In contrast, $\theta$ plays no role in the driving force for unsaturated flow and simply adjusts to bring about the required potential. Consequently, $\psi$ is a smooth function even in heterogeneous systems while $\theta$ varies in space as a reflection of the underlying heterogeneity. As the surface flux is increased, the effect of the fine-scale heterogeneities on $\theta$, for example within the dike, is less apparent. However, differences between the coarse and fine textures persist.

Simulated water contents of 0.15 to $0.20 \mathrm{~m}^{3} \mathrm{~m}^{-3}$ in the coarser sediments and 0.30 to $0.40 \mathrm{~m}^{3} \mathrm{~m}^{-3}$ in the fine sediments for $J_{w}^{0}=10^{3} \mathrm{~mm} \mathrm{yr}^{-1}$ (Figure 24d) are consistent with observations at the experimental site. Higher water contents, however, do not necessarily mean higher transport velocities. Owing to the dependence of $\mathrm{K}$ on $\theta$, it is often assumed that higher $\theta$ corresponds to higher transport velocities. Although this may be the case in homogeneous systems or those described by a single set of effective properties, it is not true in complex environments. 


\subsubsection{Subsurface Flow Networks and their Relation to Surface Flux}

The strong dependence of $\mathrm{K}$ on $\theta$ results in a much larger range of $\mathrm{K}$ than is observed in the distributions of $\theta$ (Figure 25). The effects of variability in the $\theta(\psi)$ function, coupled with the differences in air entry pressure, can cause internal water fluxes to range over several orders of magnitude. These fluxes can even exceed the input flux, and may lead to different flow networks depending on the input flux. These phenomena are clearly illustrated in Figure 25, which plots the normalized vertical flux, i.e., the node centered flux, $\left|\mathrm{J}_{\mathrm{w}}\right|$ as a ratio to the input flux, $J_{w}^{0}$. It is clear that the underlying heterogeneity leads to the development of a complicated flow network that does not reflect the distribution of $\theta$. Furthermore, these networks may even mask the underlying structure of the heterogeneity. At low input fluxes, water content is highest in the fine-textured regions of the domain, and $\mathrm{K}$ is therefore highest in those regions

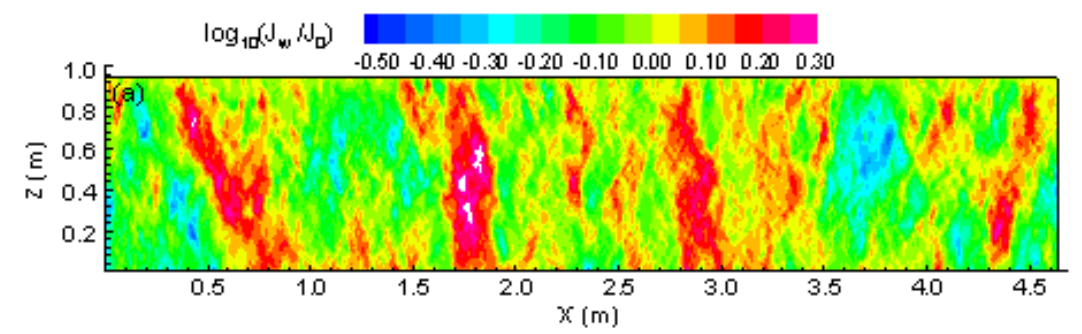

(a)

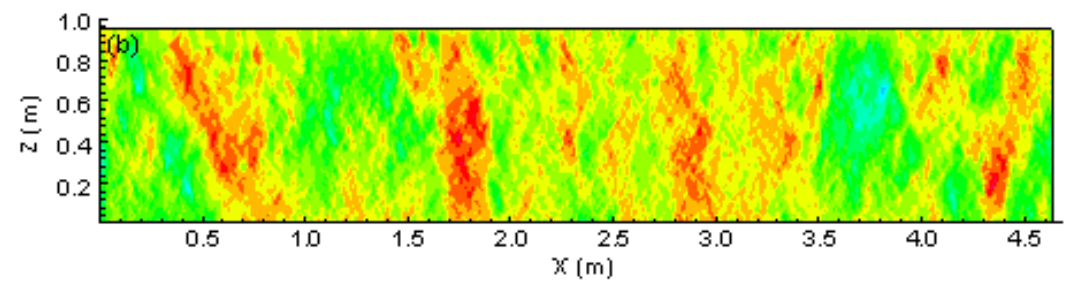

(b)

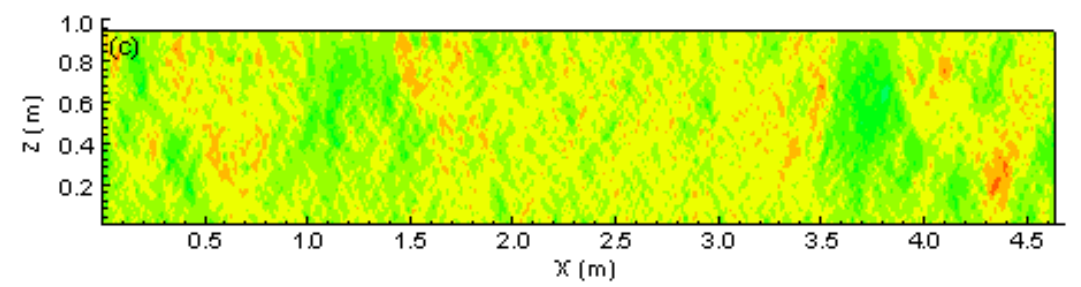

(c)

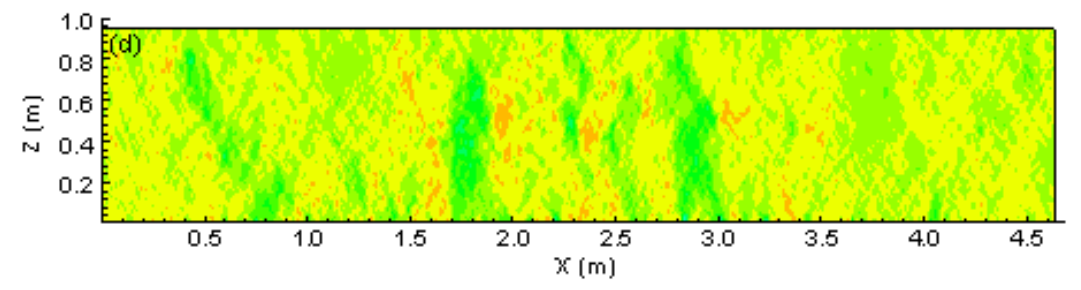

(d)

Figure 25. Distributions of Dimensionless Water Flux, $\left|\mathrm{J}_{\mathrm{w}}\right| / \mathrm{J}_{\mathrm{w}}^{0}$, During Steady Infiltration Under a Constant Flux Surface Flux, $\mathrm{J}_{\mathrm{w}}^{0}$, of (a) $1 \mathrm{~mm} \mathrm{yr}^{-1}$, (b) $10 \mathrm{~mm} \mathrm{yr}^{-1}$, (c) $10^{2} \mathrm{~mm} \mathrm{yr}^{-1}$, and

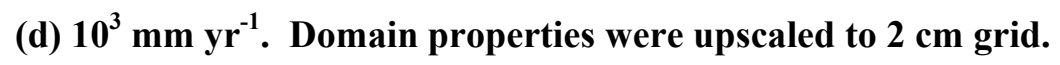


(Figure 25a). Flow channels, therefore, form at or near the upper boundary and propagate downward flowing the paths of highest conductivity. In the early stages of infiltration, the origin and distribution of these paths are clearly dependent on the underlying structure of the heterogeneity with water being redirected or funneled from regions of low conductivity to regions of high conductivity. Once the channel has formed, it transmits enough water to overcome the water entry pressure of low permeability regions resulting in wetting of small isolated regions. Larger regions of low permeability, however, would require larger amounts of water to overcome the water entry than might be available from these channels, and consequently, flow is diverted around these regions at low input fluxes. This is clearly illustrated in Figures 25a,b,c in the coarse textured region near $\mathrm{x}=3.6 \mathrm{~m}$. Water is diverted around this region until the input flux reaches $10^{1} \mathrm{~cm} \mathrm{~s}^{-1}$ while smaller regions within the dike, e.g., at $\mathrm{x}=2.5 \mathrm{~m}$, show increased velocities at much lower fluxes.

As the input flux increases, the differences in $\mathrm{K}(\theta)$ between the different textures become less as $\psi$ approaches the value at which $\mathrm{K}(\theta)$ is equal. Consequently, the differences in the flux ratio become less apparent. As shown in Figure 25c, both the coarse and fine regions show similar flux ratios when the input flux is around $10^{2} \mathrm{~mm} \mathrm{yr}^{-1}$. As the input flux is increased, $\log (-\psi)$ continues to decrease and $\mathrm{K}(\theta)$ of the coarse-textured regions surpasses that in the fine-textured regions (Figures 25c,d). Consequently, a reversal in the distribution of the flux ratio becomes apparent, and regions that were being bypassed earlier due to lower permeability become the dominant regions of transport (Figure 25d). In general, the flow networks are predominantly vertical.

It is clear that formation of these preferential channels is completely controlled by the structure of the small-scale heterogeneity seen in Figure 19. However, propagation and persistence is somewhat more complex and appears to be dominated by heterogeneities at the larger scale, as these tend to redirect flow at low fluxes. Representation of such phenomena requires, in the least, a multidimensional mechanistic model that reflects the dominant components of the underlying heterogeneity structure. These phenomena cannot be simulated with 1D models, particularly the screening models used to date for retrieval performance evaluations performed at the Hanford Site. These results are consistent with the two complimentary flow networks hypothesized from the field experiments, as well as the results of theoretical analyses reported in the literature (e.g., Roth 1995; Birkholzer and Tsang 1997).

The modeling and experimental results provide insight into the existing distribution of contaminants in the subsurface and possibly the breakthrough behavior of contaminants at the water table. The larger the input flux, the larger the local potential gradients, and the larger the number of flow paths which are reached by water and dissolved solutes. The nature of the flow paths depend strongly on how they are formed near the surface; therefore, under certain conditions, multi-peaked breakthrough curves might be observed. The shape of breakthrough curves would be expected to change as the input flux varies. As the input flux increased, breakthrough curves could be expected to change from multipeaked at low fluxes to a single peak at the critical flux when the flow networks are similar and back to multipeaked as the network switched from high permeability fine textured regions to high permeability coarse textured regions. The travel time characteristics would also be expected to change. Figure 26 compares the breakthrough of bromide observed at the $0.8 \mathrm{~m}$ monitoring depth in the host matrix and the dike. 
Despite the complexity of the internal structure, the bimodal breakthrough in the dike can be attributed simply to the existence of the two flow networks within the dike itself. A dike that is continuous to the water table could result in a similar type of distribution at the water table. These results also suggest that contaminants deposited in the vadose zone under one type of recharge of condition may subsequently become inaccessible unless similar conditions reoccur. Thus, contaminants deposited under rapid, large volume leaks could be bypassed under normal recharge conditions and vice versa. The implications of these observations are significant as they suggest the possibility of hydraulically manipulating the subsurface flow network to enhance contaminant removal or to reduce remobilization.

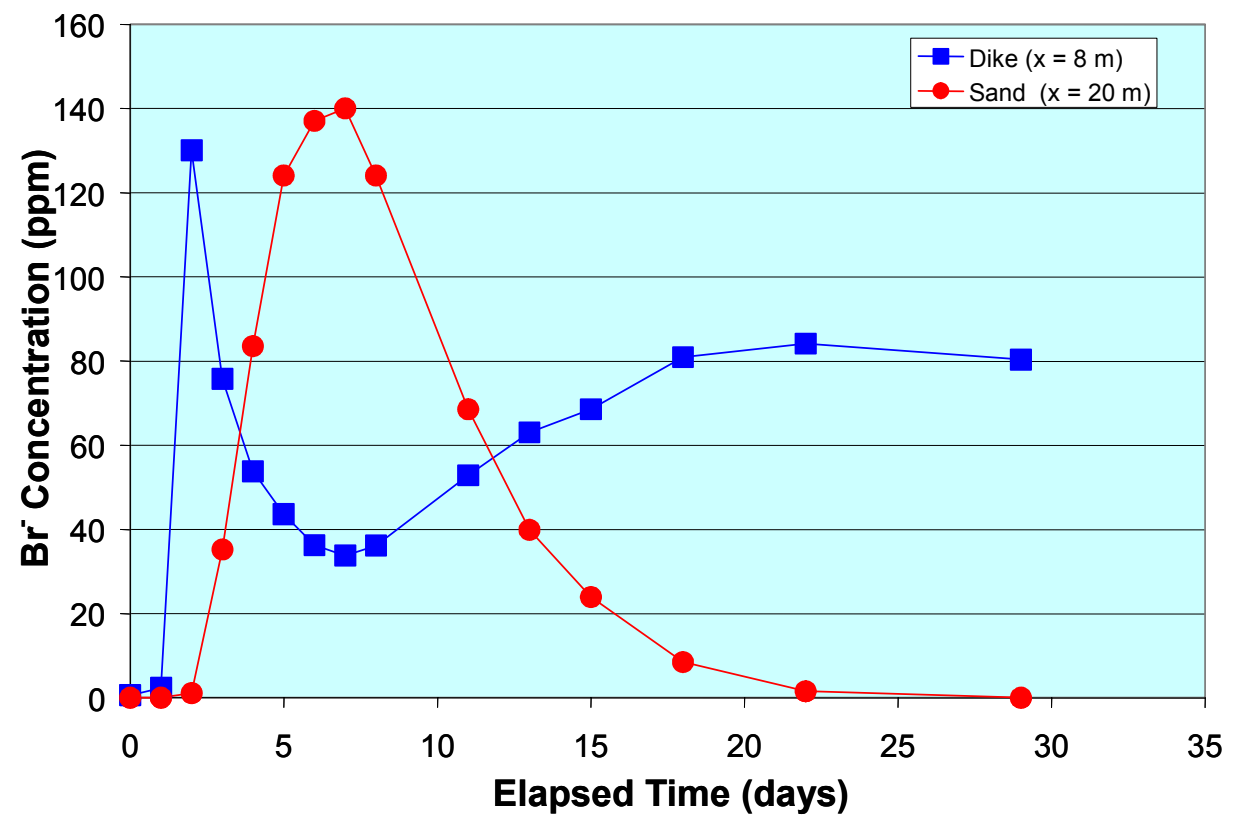

Figure 26. Example of Solute Breakthrough Curves Observed at the Army Loop Road Dike Site. Breakthrough in the dike is multimodal, reflecting at least two flow domains. A dike continuous to a compliance plane could result in multipeaked breakthrough curves at that plane.

\subsection{Relevance, Impact, and Technology Transfer}

Development of closure plans for tank farms and other waste management areas requires accurate conceptual models for vadose zone transport. There has been much speculation about the impact of clastic dikes on flow and transport through the vadose zone. Until now there have been no controlled field-scale studies of these features. Previous modeling attempts have failed due to a combination of inappropriate conceptual models, the application of simplified analytical and numerical models, an inappropriate choice of local-scale model parameters, and a failure to employ robust parameter upscaling techniques. An improved understanding of dikes is needed to support development of retrieval performance evaluations and closure plans for tank farms and other waste management areas at Hanford. This research evaluated the hypothesis that clastic dikes at the Hanford Site provide preferential pathways that enhance the 
vertical movement of moisture and contaminants through the vadose zone. To address those scientific needs, our research combined field and modeling studies of the spatial distribution of clastic dikes, with an analysis of the hydrologic properties within dikes to determine the potential effect of clastic injection dikes on fluid flow through the vadose zone.

Our research provided advances in several areas:

- Information on the large-scale geometry of the clastic dike networks, including development of an algorithm for generation of realistic 2D simulations of clastic dike networks.

- Detailed information on the geometry and hydraulic properties of clastic dikes that can be used in future modeling efforts.

- Generation of mm-scale simulations of the air permeability and hydraulic properties.

- Photogrammetric techniques for automated textural segmentation of outcrop images and millimeter estimation of hydraulic properties.

- The application and refinement of techniques for upscaling model parameters from the measurement scale to the scale of the model grid that were recently developed with the support of EMSP Project 70187 ("Quantifying Vadose Zone Flow and Transport Uncertainties Using a Unified, Hierarchical Approach”, Philip Meyer, PI).

The integration of these developments have led to the successful simulation of unsaturated flow through clastic dikes in the vadose zone. Model results and field observation show the existence of two complementary flow networks that depend on saturation, input flux, and boundary type. At low input fluxes, a high-permeability network exists in the fine-textured dike and has the potential to enhance the migration of water and mobile contaminants. At high fluxes, the high-permeability network switches to the coarsetextured host matrix. These findings provide insight into existing contaminant distributions and episodic contaminant breakthrough at the water table. Results of this study will be invaluable to optimal design of remedial systems.

\subsection{Project Productivity}

The project accomplished all major goals set forth in the proposal. The modeling studies were delayed due to the difficulty in determining the input parameters for the model, which required additional field sampling, laboratory measurements, and data analysis. One modification made from the original plans was the use of $2 \mathrm{D}$ modeling approaches in the flow modeling. The major reason for this modification was the ability of the project to estimate the hydraulic properties of the dike-matrix system at much finer resolution than originally expected. The extremely large number of grid cells that the fine-resolution models entailed, however, meant that 3D simulations of unsaturated flow were beyond the capabilities of currently available computers. The highest-resolution models of the dike matrix system that we generated (involving approximately 3.6 million nodes for the $4.64 \times 0.95 \mathrm{~m}$ domain) could not be solved on a 
desktop computer but have been solved with a parallel version of STOMP on the EMSL Opus mainframe. Techniques developed in this study have also formed the basis for estimating transport properties for modeling reactive transport in highly heterogeneous media. Full three-dimensional simulations of flow and reactive transport are now within reach, based partly on the accomplishments of this study.

\subsection{Personnel Supported}

Dr. Christopher Murray, Pacific Northwest National Laboratory (PI)

Dr. Michael Fayer, Pacific Northwest National Laboratory (Co-PI)

Dr. Anderson Ward, Pacific Northwest National Laboratory

Dr. Philip Long, Pacific Northwest National Laboratory

Dr. Gamal Seedahmed, Pacific Northwest National Laboratory

Dr. YuLong Xie, Pacific Northwest National Laboratory (postdoctoral associate)

Dr. John L. Wilson, New Mexico Institute of Mining and Technology (Co-PI, collaborator)

Benjamin J. Lechler, New Mexico Institute of Mining and Technology (MS student)

Zak Brown, New Mexico Institute of Mining and Technology (MS student)

Dr. William Clement, Boise State University (collaborator)

\subsection{Publications}

Brown, Z. 2001. Upscaling of Gas Permeameter Measurements and Adjoint Theory. MS Thesis, New Mexico Institute of Mining and Technology, Socorro, New Mexico.

Fayer, M. J., C. J. Murray, D. G. Horton, P. E. Long, G. W. Gee, A. L. Ward, J. Wilson, and W. Clement. 2000. Hydrogeological Measurements and Hydrofacies Models of Clastic Dikes at the Hanford Site, Southcentral Washington. EOS Trans. AGU, 81(48):412.

Lechler, B. J. 2002. Modification of Existing and Development of New Methods for the Measurement of the Permeability of Geologic Materials Using Air-Minipermeameters. MS Thesis, New Mexico Institute of Mining and Technology, Socorro, New Mexico. 
Murray C. J., A. L. Ward, J. L. Wilson, P. E. Long, B. J. Lechler, W. P. Clement, P. K. Kannberg, and G. W. Gee. 2001. "The Effects of Clastic Dikes on Vadose Zone Transport at the Hanford Site, Southcentral Washington.” EOS Trans. AGU, 82(47):H52A-0370.

\subsection{Interactions}

Fayer, M. J., C. J. Murray, D. G. Horton, P. E. Long, G. W. Gee, A. L. Ward, J. Wilson, and W. Clement. 2000. Hydrogeological Measurements and Hydrofacies Models of Clastic Dikes at the Hanford Site, Southcentral Washington. Presented at the American Geophysical Union Fall Meeting, San Francisco, California, December 15, 2000.

Fayer, M. J., C. J. Murray, and J. L. Wilson. 1999. "Influence of Clastic Dikes on Vertical Migration of Contaminants in the Vadose Zone at Hanford." Presentation to FY 2000 EMSP National Workshop, Richland, Washington, November 1999.

Murray, C. J. 2002. "Properties of Hanford Clastic Dikes." Presentation to DOE and Hanford Site contractor earth scientists in Richland, Washington. Presentation arranged by the DOE-RL Science and Technology Program Manager, May 9, 2002

Murray, C. J., A. L. Ward, J. L. Wilson, P. E. Long, B. J. Lechler, W. P. Clement, P. K. Kannberg, and G. W. Gee. 2001. "The Effects of Clastic Dikes on Vadose Zone Transport at the Hanford Site, Southcentral Washington." Presented at the American Geophysical Union Fall Meeting, San Francisco, California, December 14, 2001.

Murray, C. J, M. J. Fayer, D. Horton, N. Cadoret, P. Long, J. Wilson, and W. Clement. 2000. "Hydrogeological Measurements and Hydrofacies Models of Clastic Dikes at the Hanford Site, Southcentral Washington." Presented at the SEPM/IAS Research Conference on Environmental Sedimentology: Hydrogeology of Sedimentary Aquifers, Santa Fe, New Mexico, September 24-27, 2000.

Murray, C. J, M. J. Fayer, D. Horton, A. L. Ward, G. W. Gee, P. E. Long, J. L. Wilson, W. Clement. 2000. "Influence of Clastic Dikes on Vertical Migration of Contaminants in the Vadose Zone at Hanford - November 2000." Presentation to FY 2001 EMSP National Workshop, Richland, Washington, November 2000.

Murray, C. J, A. L. Ward, P. E. Long, Y.-J. Chien, F. Zhang, P. Kannberg, R. Kirkham, G. Gee, D. Horton, M. Fayer, J. L. Wilson, B. J. Lechler, and W. Clement. 2001. "Influence of Clastic Dikes on Vertical Migration of Contaminants in the Vadose Zone at Hanford - November 2001." Presentation to FY 2002 EMSP National Workshop, Richland, Washington. November 2001.

Murray, C. J., M. Fayer, D. Horton, N. Cadoret, P. Long, J. Wilson, and W. Clement. 2000. "Influence of Clastic Dikes on Vertical Migration of Contaminants in the Vadose Zone at Hanford: Status Report." FY 2000 EMSP National Workshop, Atlanta, Georgia, April 25, 2000. 
Ward, A. L. and C. J. Murray. 2002. "Hydrogeological Measurements and Infiltration Experiments at the Army Loop Road Clastic Dike Field Site.” Presented at the FY 2003 Vadose Zone Transport Workshop, Richland, Washington, December 16, 2002. The workshop was sponsored by the Hanford Groundwater Protection Program's Science and Technology (S\&T) Project.

Ward, A. L., C. J. Murray, G. W. Gee, Y. Xie, F. Zhang, and G. H. Seedahmed. 2003. "Effects of Clastic Intrusions on Flow in the Vadose Zone." Presented at the March 2003 Hanford Site Groundwater Protection Program Open Meeting in Richland, Washington, March 3, 2003.

\subsection{Transitions}

The results of this work are being prepared for publication as a full length report, in order to capture all data and models generated by the study. Selected results will also be prepared for journal publication. Extension of the research project is being pursued through the Hanford Site Groundwater/Vadose Zone Integration Project, which includes transition of the results to contractors at the Hanford Site.

\subsection{Patents}

No patents were filed during the course of this work.

\subsection{Future Work}

This study provided valuable field and laboratory data, as well as numerical models and modeling approaches that provide insight into the importance of clastic dikes and sills for vadose zone transport. Although these results suggest that clastic dikes might be conduits for rapid transport of moisture through the vadose zone at Hanford under certain recharge or waste leak conditions, the research points out several areas where further work is needed.

One area requiring further work is field scale simulation of dikes at larger scales in 3D. The current work provides algorithms for simulating the spatial distribution of dikes in $2 \mathrm{D}$, but estimating the impact at the water table would require simulation in 3D. Limited data are available for the spatial distribution of dikes with depth, but previous work indicates that the dikes penetrate tens of meters into the subsurface, and they have been positively identified at a depth of at least $50 \mathrm{~m}$ in the Ringold Formation. However, it is not known if the deeper dikes are continuous to the surface. Several scenarios might need to be developed to account for different possible structures.

Simulation of unsaturated flow and transport at the scales discussed in the previous paragraph, however, would require further advances in scaling the properties of clastic dikes. Predictive modeling of flow and transport in heterogeneous porous media is complicated by the range of relevant size scales. Processes 
like sorption occur at the pore scale and ultimately affect transport behavior at the field scale. Multi-scale digital image based characterization, as developed in this study, is ideal for overcoming this limitation, and computations performed at one scale can be used as input at the next higher level, providing a robust method for evaluating upscaling methodologies. Work has started in this area with the ultimate goal of performing inverse modeling for the estimation of field scale parameters.

Although the results of this study suggest that moisture flow in clastic dikes might be more rapid than it would be in the surrounding matrix, the model simulations conducted for this study have focused on water flow. A natural extension of this project would be the investigation of the transport of mobile and reactive contaminants using both particle tracking and the convective dispersive equation. Even in wellinstrumented experiments, subsurface characterization of transport parameters is insufficient to allow accurate prediction of reactive transport over multiple scales of heterogeneity. The coupling of microscale hydraulic characterization techniques with digital photogrammetry and granulometry has significant potential for yielding 2-D, multi-parameter data sets at of high spatial resolution for reactive transport modeling. This approach is already being investigated under the Hanford Groundwater Protection Program's Science and Technology (S\&T) Project for use in the FY2003 vadose zone transport field studies. Coupling of these techniques with noninvasive geophysical methods like surface GPR should allow the generation of 3D parameter fields for reactive transport studies of the impact of clastic dikes on contaminant transport.

\subsection{Literature Cited}

Acuna, J. A. and Y. C. Yortsos. 1995. Application of fractal geometry to the study of networks of fractures and their pressure transient. Water Resour. Res., 31:527-540.

Alumbaugh, D., P. Y. Chang, L. Paprocki, J. R. Brainard, R. J. Glass, and C. Z. Rautman. 2002. Estimating moisture contents in the vadose zone using cross-borehole ground penetrating radar: A study of accuracy and repeatability, Water Resour. Res., 38, 1309.

Arya, L. M., F. J. Leij, P. J. Shouse, and M.Th. van Genuchten. 1999. Relationship between the hydraulic function and the particle size distribution. Soil Sci. Soc. Am. J. 63:1063-1070.

Barton, C. C. 1995. Fractal Scaling of Fracture Networks. In Fractals in the Earth Sciences, eds. C. C. Barton and P. R. LaPointe, Plenum Press, New York.

Barton, C. A. and M. D. Zoback. 1992. Self-similar distribution and properties of macroscopic fractures at depth in crystalline rock in the Cajon Pass scientific drill hole. J. Geophys. Res. 97:5181-5200.

Birkholzer, J. and C. Tsang. 1997. Solute channeling in unsaturated heterogeneous porous media. Water Resour. Res. 33:2221-2238.

Blake, G. R. and K. H. Hartge. 1986. Bulk Density. In A. Klute, ed., Methods of Soil Analysis, Part I. Physical and Mineralogical Methods: Agronomy Monograph no. 9 (2nd ed.), pp. 363-375. 
Brooks, R. H. and A. T. Corey. 1964. Hydraulic properties of porous media. Hydrology Paper no. 3. Colorado State University, Fort Collins, Colorado.

Burdine, N. T. 1953. Relative permeability calculations from pore-size distribution data. Trans. AIME, 198:71-77.

Campbell, G .S. 1974. A simple method for determining unsaturated conductivity from moisture retention data. Soil Sci. 117:311-314.

Cowie, P. A., R. J. Knipe and I. G. Main, eds. 1996. Special Issue: Scaling laws for fault and fracture populations-Analyses and applications. J. Structural Geology, 18:135-383.

Davis, J. C. 2002. Statistics and Data Analysis in Geology. John Wiley \& Sons, Inc., New York.

Deutsch, C. V. and Cockerham, P. W. 1994. "Practical Considerations in the Application of Simulated Annealing to Stochastic Simulation," Mathematical Geology 26(1):67-82.

Deutsch, C. V. and A. G. Journel. 1998. GSLIB: Geostatistical Software Library and User's Guide. Oxford University Press, New York.

Gee, G. W. and J. W. Bauder. 1986. Particle Size Analysis, in Methods of Soil Analysis, Part 1, ed. A. Klute, pp. 383-409. American Society of Agronomy, Madison, Wisconsin.

Fecht, K. R., K. A. Lindsey, B. N. Bjornstad, D. G. Horton, G. V. Last, and S. P. Reidel. 1998. Clastic Injection Dikes of the Pasco Basin and Vicinity. BHI-01003, Draft A, Bechtel Hanford Inc., Richland, Washington.

Jolly, R. J. H., J. W. Cosgrove, and D. N. Dewhurst. 1998. Thickness and spatial distributions of clastic dykes, northwest Sacramento Valley, California. J. Structural Geology 20(12):1663-1672.

Khaleel, R. 1999. Far-Field Hydrology Data Package for Immobilized Low-Activity Tank Waste Performance Assessment. HNF-4769 Rev. 1, Fluor Federal Services, Richland, Washington.

Long, P. E., H. P. Foote, S. M. Goodwin, C. S. Kimball, C. J. Murray, J. L. Wilson and R. G. Taylor. 1996. Use of ultrasensitive infrared imaging to provide detailed permeability estimates for microbial transport experiments. EOS 77(46):F221.

Meyer, P. D., M. L. Rockhold, C. J. Murray, and Y.-J. Chien. 2002. "Uncertainty Assessment of a Parameterization Method for Vadose Zone Modeling," Eos Trans. AGU, 83(47), Fall Meet. Suppl., Abstract H22F-01. (Presentation at the 2002 Fall Meeting of the American Geophysical Union, San Francisco, California)

Moeur, M. 1993. "Characterizing spatial patterns of trees using stem-mapped data." Forest Science 39(4):754-775. 
Oostrom, M. and R. J. Lenhard. 1998. Comparison of relative permeability-saturation-pressure parametric models for infiltration and redistribution of a light nonaqueous phase liquid in sandy porous media. Adv. in Water Reso. 21:145-157.

Reynolds, W. D., and D. E. Elrick. 1985. In situ measurement of field-saturated hydraulic conductivity, sorptivity, and the $\alpha$-parameter using the Guelph permeameter, Soil Sci. 140 (4), 292-302.

Rockhold, M. L., C. J. Murray, and M. J. Fayer. 1999. “Conditional simulation and upscaling of soil properties.” pp. 1391-1402. In: Proceedings of the International Workshop on Characterization and Measurement of the Hydraulic Properties of Unsaturated Porous Media. M. Th. van Genuchten, F. J. Leif, and L Wu (eds.). University of California, Riverside, California.

Rockhold, M. L., P. D. Meyer, Y.-J. Chien, and C. J. Murray. 2002. "Effects of Model Grid Resolution and Parameter Upscaling on Predictions of Water Flow in Heterogeneous, Unsaturated Porous Media," Eos Trans. AGU, 83(47), Fall Meet. Suppl., Abstract H62B-0863. (Presentation at the 2002 Fall Meeting of the American Geophysical Union, San Francisco, California)

Roth, K. 1995. Steady state flow in an unsaturated, two-dimensional, macroscopically homogeneous Miller-similar medium. Water Resour. Res. 31:2127-2140.

Tidwell, V. C. and J. L. Wilson. 1997. Laboratory method for investigating permeability upscaling, Water Resour. Res. 33(7):1607-1616.

Topp, G. C., J. L. Davis, and A. P. Annan. 1980. Electromagnetic determination of soil water content: Measurements in coaxial transmission lines, Water Resources Research, 16, 574-582.

Ward, A. L., G. W. Gee, and M. D. White. 1997. A comprehensive analysis of contaminant transport in the vadose zone beneath tank SX-109. PNNL-11463, UC-702. Pacific Northwest National Laboratory, Richland, Washington.

White, M. D. and M. Oostrom. 2000. STOMP - Subsurface Transport Over Multiple Phases, Version 2.0, Theory Guide, PNNL-12030, Pacific Northwest National Laboratory, Richland, Washington.

Youngs, E. G. 1964. An infiltration method for measuring the hydraulic conductivity of unsaturated porous materials. Soil Sci. 91:307-311.

Zhang, R. 1997. Determination of soil sorptivity and hydraulic conductivity from the disk infiltrometer. Soil Sci. Soc. Am. J. 61:1024-1030.

Zhang, Z. F., A. L. Ward, and G. W. Gee. 2003. Describing the unsaturated hydraulic properties of anisotropic soils using a tensorial connectivity-tortuosity (TCT) concept. Vadose Zone J. (in press). 
Zhang, Z. F., A. L. Ward, G. W. Gee, and M. D. White. 2002. "Parameter Estimation for Unsaturated Layered Soils Through a Combination of Non-similar Media Scaling and Inverse Flow Modeling." In: IAHR International Groundwater Symposium "Bridging the Gap between Measurement and Modeling in Heterogeneous Media," International Groundwater Symposium, Berkeley, California, March 25-28 (n press). 